\title{
DEPOCEN
}

Working Paper Series No. 2011/01

\section{Wal-Mart as Catalyst to U.S.-China Trade}

\author{
Emek Basker* \\ Pham Hoang Van**
}

\begin{abstract}
* University of Missouri
** Baylor University; Comments welcome to: emek@missouri.edu and van pham@baylor.edu. A previous version circulated under the title "Putting a Smiley Face on the Dragon: Wal-Mart as Catalyst to U.S.-China Trade." We thank Daron Acemoglu, Saku Aura, Jeff Campbell, Bengte Evenson, Gary Gereffi, Jonathan Haskel, Tom Hubbard, Shawn Klimek, Guy Michaels, Peter Mueser, Leonard Nakamura, Michael Noel, John Romalis, John Stevens, Ken Swinnerton, Vitor Trindade, Xinghe Wang, Jeff Wilder, Kei-Mu Yi, and seminar participants at Missouri, Federal Reserve Board of Governors, Nevada-Las Vegas, Kentucky, Census Bureau, Berkeley, Baltimore, Baylor, Northwestern, Oregon, UCSD, MIT, Federal Reserve Banks of Philadelphia and Chicago, LSE, QMUL, and the 2005 Missouri Economic Conference, 2005 NEUDC (Providence), 2006 AEA (Boston), and 2006 IIOC (Boston) for comments. Any remaining errors are our own.
\end{abstract}

The DEPOCEN WORKING PAPER SERIES disseminates research findings and promotes scholar exchanges in all branches of economic studies, with a special emphasis on Vietnam. The views and interpretations expressed in the paper are those of the author(s) and do not necessarily represent the views and policies of the DEPOCEN or its Management Board. The DEPOCEN does not guarantee the accuracy of findings, interpretations, and data associated with the paper, and accepts no responsibility whatsoever for any consequences of their use. The author(s) remains the copyright owner. 


\title{
Wal-Mart as Catalyst to U.S.-China Trade
}

\author{
Emek Basker \\ University of Missouri \\ Pham Hoang Van*
Baylor University
}

April 2008

\begin{abstract}
Retail chains and imports of consumer goods from developing countries have grown sharply over the past 25 years. Wal-Mart's sales, which currently account for $15 \%$ of U.S. imports of consumer goods from China, grew 90 -fold over this period, while U.S. imports from China increased 30-fold. We relate these trends using a model in which scale economies in retail interact with scale economies in the import process. Combined, these scale economies amplify the effects of technological change and trade liberalization, creating a two-way relationship between the chain's size and its sourcing choice. Falling trade barriers increase imports not only through direct reduction of input costs but also through an expanded chain and higher investment in technology. Calculations based on our model suggest that the existence of the chain more than doubles the sensitivity of imports to tariff reductions. Technological innovations account for approximately $60 \%$ of Wal-Mart's growth from 1984-2004 and reductions in input cost, due to tariff reductions and changes in sourcing, account for $40 \%$ of this growth.
\end{abstract}

JEL Codes: L11, L81, F12

Keywords: Wal-Mart, Trade, Economies of Scale, China, Technological Change, Retail Chain

*Comments welcome to: emek@missouri.edu and van_pham@baylor.edu. A previous version circulated under the title "Putting a Smiley Face on the Dragon: Wal-Mart as Catalyst to U.S.-China Trade." We thank Daron Acemoglu, Saku Aura, Jeff Campbell, Bengte Evenson, Gary Gereffi, Jonathan Haskel, Tom Hubbard, Shawn Klimek, Guy Michaels, Peter Mueser, Leonard Nakamura, Michael Noel, John Romalis, John Stevens, Ken Swinnerton, Vitor Trindade, Xinghe Wang, Jeff Wilder, Kei-Mu Yi, and seminar participants at Missouri, Federal Reserve Board of Governors, Nevada-Las Vegas, Kentucky, Census Bureau, Berkeley, Baltimore, Baylor, Northwestern, Oregon, UCSD, MIT, Federal Reserve Banks of Philadelphia and Chicago, LSE, QMUL, and the 2005 Missouri Economic Conference, 2005 NEUDC (Providence), 2006 AEA (Boston), and 2006 IIOC (Boston) for comments. Any remaining errors are our own. 


\section{Introduction}

In this paper, we study the relationship between the structure of retail markets in the U.S. and the volume and source of consumer-goods imports. The most striking change in retail markets over the past 25 years has been an increase in the size and prevalence of "big box" chains, most spectacularly among them Wal-Mart, which has experienced a ten-fold growth in the number of stores. Imports from developing countries have also increased dramatically over this period; China's imports to the U.S. expanded 30-fold in real terms. Wal-Mart's imports have increased even faster: while the chain now handles $6.5 \%$ of U.S. retail sales, it accounts for over $15 \%$ of U.S. imports of consumer goods from China. We present a theory that links these trends and show that there is a two-way relationship between the size of a dominant retailer and imports of consumer goods. The model can explain a number of observed patterns, including the concurrent and accelerating expansion of Wal-Mart and U.S. imports from China despite only modest reductions in trade barriers and the collapse of Wal-Mart's "Buy American" campaign in the early 1990s.

We focus on Wal-Mart because it has become the canonical example of a large retail chain and because the claim has been made repeatedly in the popular press that Wal-Mart imports more than other retailers and that its purchasing decisions have influenced trade patterns. A 2003 Pulitzer Prize-winning series on Wal-Mart in the Los Angeles Times claimed that "Wal-Mart is so powerful that it moves the economies of entire countries, bringing profit and pain," and, more specifically, that Wal-Mart "has hastened the flight of U.S. manufacturing jobs overseas" (Goldman and Cleeland, 2003). A 2004 PBS documentary focused on the "clash between the interests of Americans as workers and the desires of Americans as consumers" inherent in Wal-Mart's "everyday low prices." ${ }^{1}$ Less ominously, the Economist argues that "the emergence of China as a centre of low-cost production is playing to [WalMart's] strengths" (The Economist, 2004). These arguments are consistent with Bernard,

\footnotetext{
${ }^{1}$ See http://www.pbs.org/wgbh/pages/frontline/shows/walmart/etc/synopsis.html.
} 
Jensen, and Schott's (forthcoming) finding, using the Longitudinal Business Database and detailed firm-level data on trade transactions, that larger firms are disproportionately engaged in trade: they import (and export) more products, from more countries, and at much higher rates per worker than smaller firms.

In our model, the relationship between chain size and imports emerges from an interaction between economies of scale in retailing and economies of scale in the import process. We focus on a chain retailer with a fixed (later, endogenous) "chaining" technology that determines its cost of logistics and distribution. The chain has economies of scale in marketing, which we model as a declining marginal cost. A second source of economies of scale arises because there are two input markets, one domestic and one foreign, and there is a fixed cost associated with purchasing the input from the foreign market. As a result, the chain needs to reach a threshold size before it begins to import. These factors combine to generate an equilibrium that depends on the chain's technology. Technological improvements increase the chain's optimal size, reducing its marginal input cost; the lower retail price that results increases quantity demanded in each of the chain's stores. When the chain becomes sufficiently large it switches from domestic to offshore suppliers. The movement of production overseas further reduces marginal cost, increasing the chain's profit per store and giving it an added incentive to expand.

The expansion of the chain increases market size and, at the same time, feeds on this larger market. The idea that market size affects production patterns, which dates back to Adam Smith (1776), has been studied extensively in the trade literature. ${ }^{2}$ We build on it using a model similar to Jones and Kierzkowski (1990) in which production is described as a set of blocks linked to form a supply chain. Outsourcing a production block entails a fixed linking cost, so the size of the market determines the extent of outsourcing. ${ }^{3,4}$ In our model,

\footnotetext{
${ }^{2}$ See for example Helpman and Krugman (1985), Ethier (1979), and Belassa (1967).

${ }^{3}$ See also Wan (2005) and Long, Riezman, and Souberyan (2005) for models extending this idea.

${ }^{4}$ To focus on the main issues of this paper we ignore the distinctions among the different forms these links can assume, i.e., whether the foreign producer is a subsidiary, subcontractor, or independent exporter,
} 
the extent of outsourcing also affects the size of the market, operating through the chain store.

The relationship between these two scale economies amplifies the effect of trade liberalization on import volume. A lower tariff not only expands imports through the usual effect on price but also causes the retailer to expand the chain. The expanded chain brings imports to more locations and reduces the retailer's marginal cost, causing a further expansion of the market for imports. Accounting for these additional effects due to the chain's expansion more than doubles the effective elasticity of demand for imports relative to standard models that only consider the direct effect of a tariff reduction.

The retail chain's costs add an endogenous layer to the gap between manufacturers' production costs and consumer prices. In neoclassical international trade models this gap is due solely to frictions such as tariffs and transport costs. Trade models with monopolistic competition increase the gap by adding the monopolist's markup. We introduce the retail chain's cost which further increases the wedge between production costs and consumer prices. Because economies of scale cause the retail chain to expand as tariffs fall, this added wedge shrinks endogenously, amplifying the effect of a tariff reduction. The shrinking wedge can help explain the observed nonlinear relationship between tariff reductions and trade volume noted by, among others, Yi (2003), Romalis (2005), and Ruhl (2008). In the case of China, a large tariff reduction with the granting of Most Favored Nation status in 1980 had a relatively small effect on exports to the U.S., while modest tariff reductions in later years have generated much larger increases in exports.

A related point is that, because trade liberalization increases the retailer's incentive to expand, it leads to increased downstream concentration. This result is new to the literature and complements the result of recent models by Alessandria and Choi (2007), Melitz (2003),

etc. Several recent papers have examined these contractual arrangements in detail (see Antràs, 2003; Antràs and Helpman, 2004; Grossman and Helpman, 2002a,b). Of particular interest for our context are Feenstra and Hanson's (2005) study of outsourcing in China and Javorcik, Keller, and Tybout's (2006) paper on the effect of Wal-Mart's Mexican operations on the that country's soap and detergent industry. 
and Bernard, Redding, and Schott (2006), all of which find effects of productivity shocks and trade liberalization on exporting firms. The only other paper we are aware of that connects retail activity and trade barriers is by Campbell and Lapham (2004), who empirically evaluate the effect of U.S.-Canada exchange rate fluctuations on cross-border retail shopping. Our setting allows for exchange rate and other input cost fluctuations to affect a much wider swath of consumers because the chain, as importer, brings goods to all its stores.

For our purposes, China serves both as an embodiment of a more general phenomenon and as a special case. To a large extent, our model applies to Vietnam, Bangladesh, and Taiwan as much as it applies to China. But an extension of our model in which we allow for a continuum of possible production locations reveals a sense in which China is different. If the retailer's technology improves (for either exogenous or endogenous reasons), it contracts with producers in ever-farther locations, increasingly taking advantage of lower production costs. This is perhaps most relevant to the rise of Wal-Mart because Wal-Mart specializes in relatively low-end products whose production does not require large investments in human and physical capital. China is the current locus of this process. This interpretation is consistent with the sentiment of some developing economies that industries are being lost to China (see, for instance, Moreira, 2007) over a period when U.S. import tariff rates have declined at similar rates for all countries. As production moves across countries and regions, the chain takes advantage of falling costs by growing even more, further magnifying the chain's effect on import volume. As a result, trade liberalization that affects all an importing country's (current and potential) trading partners equally can cause production to shift from one country to another. In other words, greater potential access to an export market can reduce a country's exports if the same measure also increases competition from other countries.

Although we emphasize the role of the retailer as a direct importer, this is obviously only part of the story. Many imports arrive on retailers' shelves via intermediaries: wholesalers, merchandisers, or manufacturers. (Bernard, Jensen, and Schott (forthcoming) find that re- 
tailers and wholesalers make up a large and increasing share of importing firms, but they do not distinguish between the two sectors.) A final extension embeds our model in a framework in which the chain retailer can choose to import directly or through an intermediary. Because importing directly involves duplicating the intermediary's costs, if the intermediary can charge the chain and smaller retailers different prices, the solution with indirect imports always dominates. Indirect importing creates an additional price wedge due to double marginalization: both the intermediary and the retailer charge a markup over marginal cost. Like the retailer's markup, we find that the intermediary's markup is endogenous and falls with tariffs. Thus, we obtain the same qualitative results as for the direct-import case: a reduction in tariffs is amplified by a shrinking markup.

The remainder of this paper is organized as follows. Section 2 provides some facts about the recent growth of chains and imports that serve as background to our model. Section 3 describes the basic model and analyzes the effects of technological change and trade liberalization, along with extensions. Section 4 presents a numerical exercise that quantifies the contributions of scale economies, lower input costs, and better technology on the size of the retail chain and on import volumes. Section 5 concludes.

\section{Background: Chains and Imports}

Retail chains have grown dramatically over the past half-century, while stand-alone ("momand-pop") retailers have been declining. A recent study using establishment-level data from the Census Bureau covering the period 1975-2000 shows that retail chains were the driving force behind the growth in the number of retail stores and the sole source of growth in retail employment over this period. Among retail chains, national chains grew the fastest (Jarmin, Klimek, and Miranda, 2005).

Table 1 shows the increase in the size and dominance of chains over the period 19482002. In the first three columns we report, respectively, the fraction of retail firms that 
operate chains, the share of all retail stores that belong to chains, and chains' share of all retail sales. All three measures rise over time, with a distinct rise in the share of chain stores since the early 1970s. In the last three columns we report the same three measures but for large chains (with 100 or more stores) relative to all chains; large chains have been gaining market share relative to smaller chains throughout this period.

These trends may be explained by advances in technology that increasingly raise chains' cost advantage over stand-alone retailers. Although available measures of productivity and efficiency for the retail industry are relatively poor, chains appear to be more productive than stand-alone retailers and they invest more in information technology (Doms, Jarmin, and Klimek, 2004). Foster, Haltiwanger, and Krizan (2002) show that the bulk of productivity growth in the U.S. retail sector in the 1990s came from the expansion of more-productive retail chains and the contraction and exit of less-productive retailers, and that the retail sector exhibits large and persistent productivity differences across establishments within narrow (4-digit) industries.

There is evidence that bigger retail firms tend to import more. Bernard, Jensen, and Schott (forthcoming) find that the size distribution of importing firms is much more skewed than the overall size distribution of firms; the largest firms import disproportionately more than their size would suggest. In a study across retail sectors, Basker and Van (2008) find that the largest retail chains are substantially more likely than smaller retailers to import from less-developed countries (LDCs). For example, the largest chains across all retail sectors increase imports by 10 cents for every dollar increase in sales whereas the smaller retailers increase imports an average of less than 3 cents per dollar of sales.

Wal-Mart is the largest retail chain in the United States (and the world). The chain has expanded steadily since opening its first store in Rogers, Arkansas, in 1962; by 2004, it had more than 3,000 stores in all 50 states and about 800,000 employees in the U.S. and accounted for $6.5 \%$ of all U.S. retail sales. Figure 1 shows U.S. Wal-Mart sales in real 2002 
dollars over the period 1978-2004 as a thick line (using the right-hand axis). ${ }^{5}$ Figure 2 separates Wal-Mart's sales growth since 1985 into two components: the rise in the number of Wal-Mart stores (solid line, left axis) and sales per store (dotted line, right axis). Since part of the growth in sales per store has been fueled by the rise of the "Supercenter" format which includes a full line of groceries, we also compute sales per store excluding grocery sales. All of these rise over time. ${ }^{6}$

Wal-Mart's technological prowess, its zealous cost-cutting, and its propensity to import have all received much attention in popular discourse. Feiner, O'Andraia, Black, Jones, and Konik (2002) cite Wal-Mart's "use of technology for merchandising, distribution and replenishment" as its main advantage over other retailers (p. 217). A study by McKinsey Global Institute (2001) attributes much of the acceleration in productivity growth in the 1990s to Wal-Mart, and Holmes (2001) and Bagwell, Ramey, and Spulber (1997) also cite evidence that Wal-Mart is a leading investor in IT. In 1990, Wal-Mart introduced a technological innovation, Retail Link, software connecting its stores, distribution centers, and suppliers, providing detailed inventory data "to bring our suppliers closer to our individual stores" (Wal-Mart Stores, Inc., 1991, p. 3). Many industry observers credit Wal-Mart's subsequent dominance in the retail sector to this innovation (see, for example, Abernathy, Dunlop, Hammond, and Weil, 1999).

In 1985, Wal-Mart launched a popular and well-publicized "Buy American" campaign, pledging to "buy American whenever we can" and to pay up to a $5 \%$ premium for U.S.made goods (Zellner, 1992). In late 1992, however, Dateline NBC aired a segment charging Wal-Mart with producing private-label clothes in Bangladesh, smuggling Chinese garments into the U.S. in excess of U.S. quotas, and placing imported clothes on racks marked "Made

\footnotetext{
${ }^{5}$ Includes Sam's Club sales.

${ }^{6}$ The share of sales due to groceries has been reported since 1997 in Wal-Mart's 10-K filings; pre-1997 figures are imputed. Groceries are just the latest product line to be added by Wal-Mart, after pharmaceuticals, auto services, and others. See Basker, Klimek, and Van (2008) for details. For a general discussion of Wal-Mart's advantages and economic impact, see Basker (2007).
} 
in the USA" (Gladstone, 1992). ${ }^{7}$ References to the "Buy American" campaign disappeared from both the popular press and Wal-Mart's publications by early $1993 .{ }^{8}$ In the context of our model, Wal-Mart's abandonment of its "Buy American" campaign can be attributed to its expansion over the course of the campaign from 859 to 1880 stores, possibly passing a threshold size beyond which purchasing inputs domestically was no longer profit maximizing.

Concurrent with Wal-Mart's expansion, U.S. imports from the rest of the world, and from less-developed countries (LDCs) in particular, have surged. Between 1984 and 2004, U.S. imports from China increased more than 30-fold in real terms. Imports from China are shown in Figure 1 as a thin solid line, using the right-hand axis, on the same scale as U.S. Wal-Mart sales. ${ }^{9}$ The emergence of private label apparel that competes directly with U.S. apparel manufacturing and global sourcing of apparel production also coincided with these trends (Gereffi, 1999). This rise in imports has occurred while import tariffs on Chinese goods have fallen only modestly. The only sharp decline occurred in 1980, when China was granted Most Favored Nation (now Normal Trade Relations, or NTR) status with the U.S.; since then, tariffs on Chinese goods have fallen gradually, as part of the general reduction in NTR rates. The dotted line in Figure 1 shows, using the left-hand axis, the average (unweighted) U.S. tariff rate applicable to products exported from China for the period $1978-2000 .{ }^{10,11}$

\footnotetext{
${ }^{7}$ Gereffi and Pan (1994) rank Wal-Mart as the second-largest retail buyer in Taiwan that same year.

${ }^{8}$ Wal-Mart referred to its "Buy American" campaign as "a key philosophy of our buying divisions" in its 1987 annual report (p. 8) and reiterated its commitment to "Buy American' in every possible situation" in the 1989 annual report (p. 2). By 1994, the annual report stated (p. 6), "We wish that everything we sell was made in the United States. Today this isn't possible, but we are going to keep trying" (Wal-Mart Stores, Inc., various years).

${ }^{9}$ This figure uses the finished-goods Producer Price Index to deflate nominal import values from the U.S. Bureau of Economic Analysis. The true growth rate is probably even larger, because the composition of imports from China is skewed towards items, like apparel and toys, whose prices have been falling relative to the overall price level. Wal-Mart's sales figures include sales from its Sam's Club division.

${ }^{10}$ We thank John Romalis for providing these data from Romalis (2005). Figures for 2001-2004 are not available but do not include any sharp breaks.

${ }^{11}$ The increase in imports from China reflects increases in imports of intermediate goods and capital goods in addition to consumer goods. While our story applies directly only to consumer goods, the mechanism we describe, which operates through economies of scale and increased market size, may apply more broadly. If
} 
Many observers have speculated on a link between these concurrent trends in the retail and import sectors. Early on, Wal-Mart was one of a handful of retailers and merchandising firms that constituted the primary link between Asian manufacturers and the American market. The role of big retailers in "organizing and channeling," if not amplifying, demand for cheap imports has been noted by Petrovic and Hamilton (2005) and Feenstra and Hamilton (2006); Gereffi (1999) argues that the growth of "high volume, low cost discount chains," including Wal-Mart, has amplified global sourcing (pp. 44-45). Wal-Mart's import volume is not publicly available, but some figures have been cited in the popular press. Wal-Mart accounted for approximately $\$ 18$ billion in goods imports from China in 2004, representing over $15 \%$ of U.S. consumer-goods imports from China that year; about half of this amount refers to direct imports, the rest coming through its suppliers (The Economist, 2004). Wal-Mart's sales account for 6.5\% of U.S. retail sales (Basker, 2007), so this figure implies Wal-Mart imports from China at over twice the rate of the retail sector as a whole. Others estimate that $80 \%$ of Wal-Mart's global suppliers are located in China (Goodman and Pan, 2004) and that $70 \%$ of its products are made in China (Jiang, 2004). ${ }^{12}$ Gereffi (2006) estimates that Wal-Mart, the top U.S. apparel seller, sources $100 \%$ of its apparel from low-cost countries and also sells a much higher share of private-label apparel than other national apparel sellers ( $80 \%$ vs. an average of $35 \%$ among the top-ten apparel retailers).

A look at the relationship between apparel price inflation and Wal-Mart's market share also suggests that Wal-Mart imports disproportionately more than other apparel sellers. Using annual data on consumer price inflation in the apparel sector for 23 metropolitan areas ( $\Delta p_{i t}$, with $i$ indexing the location and $t$ indexing year), import price inflation for apparel at the national level $\left(\Delta p_{t}^{m}\right)$, and Wal-Mart's market share (WMshare ${ }_{i t}$ ) over a 19-year period,

there are increasing returns to scale in manufacturing, then declines in the cost of intermediary goods can be amplified in that sector too through a similar mechanism to the one described in this paper.

${ }^{12}$ This last figure is almost certainly exaggerated. 
we estimate a pass-through equation,

$$
\Delta p_{i t}=\beta_{1}+\beta_{2} \Delta p_{t}^{m}+\beta_{3} \mathrm{WMshare}_{i t}+\beta_{4} \Delta p_{t}^{m} \cdot \mathrm{WMshare}_{i t}+\varepsilon_{i t} .
$$

The results are shown in Table 2 for two different measures of import price inflation. ${ }^{13}$ For each measure, we report in the first column results from a regression with no covariates, where we find a positive and statistically significant relationship between the two inflation rates: a 1-point increase in apparel import price inflation corresponds to a 0.4-0.5 point increase in apparel consumer price inflation. In the second column, we add Wal-Mart's market share and the interaction term. The direct effect of Wal-Mart is to reduce apparel inflation, consistent with the common perception that Wal-Mart's presence serves as a discipline device for costs. ${ }^{14}$ The coefficient on the interaction term is positive: increasing Wal-Mart's market share from $1 \%$ to $2 \%$ - an increase of 10 stores, on average - nearly doubles the sensitivity of consumer price inflation to import price inflation. Such an effect implies that the import share of apparel sales at Wal-Mart stores is substantially higher than at the average apparel retailer. ${ }^{15}$

These results are not definitive, but they are strongly suggestive that Wal-Mart's presence is associated with a higher level of imports in an MSA, and they are consistent with the common perception that Wal-Mart acts as a catalyst to greater imports and increased global sourcing. In the next section, we suggest a mechanism that can explain this relationship.

\footnotetext{
${ }^{13}$ The data are described in full in Appendix B.

${ }^{14}$ As noted by Hausman and Leibtag (2004), the BLS's correction for sampling changes biases the indices against exhibiting a "Wal-Mart effect."

${ }^{15}$ Wal-Mart's market share is measured with error, since the number of stores in the denominator is not weighted by their sales share, and we do not control for the existence of other large chain retailers which may also import disproportionately to their size. Because these problems bias us against finding an effect, however, the estimated effect is probably a lower bound on the effect of large chains on apparel imports.
} 


\section{Model}

\subsection{Domestic Production}

There are $N$ locations or retail markets ( $N$ large), which are ex ante identical. Each location is served by a monopolist retailer selling a single consumption good. Market demand in each location, $x(p)$, is downward-sloping.

We focus on the partial-equilibrium choices of a single retailer. The retailer has access to "chaining technology" that enables it to operate a chain of $k \geq 0$ stores at a cost $\frac{c(k)}{\delta}$, where $\delta>0$ and $c(\cdot)$ is increasing and convex. ${ }^{16}$ We think of $c(k)$ as capturing the costs of adding truck routes, distribution center inventory, etc. The motivation for a positive second derivative on $c(\cdot)$ is that each additional store is accommodated by re-optimizing distribution facilities, inventory management and trucking routes, and this process becomes increasingly complex — and costly — as the network expands. Westerman (2001), for example, discusses the complications for Wal-Mart's replenishment system caused by "the growth of the company ... [into] different time zones" (page 182). ${ }^{17}$ In addition, without convex chaining costs, nothing would keep the chain from expanding to take over all retail locations; this scenario is both unrealistic and uninteresting from our point of view. The parameter $\delta$ captures the chain's level of technology: if $\delta$ is very high, then the cost of chaining is very low. We begin by treating $\delta$ as exogenous; we later endogenize it to capture the retailer's investment decision.

The retailer's role is to buy the consumption good from a manufacturer and sell it to consumers. The retailer's cost consists of two elements: the input cost of the consumption good and a marketing cost. The consumption good is produced by a competitive market

\footnotetext{
${ }^{16}$ Formally, $c(0)=c^{\prime}(0)=0, c^{\prime}>0$ for $k>0, c^{\prime \prime}>0$.

${ }^{17}$ Holmes (2008) explicitly models the expansion pattern of Wal-Mart, with a focus on "economies of density" - the cost-savings achieved when stores are located near one another. We abstract from that issue here, treating all locations as symmetric with respect to one another.
} 
using a constant-returns production technology with marginal input cost $\alpha .{ }^{18}$ The retailer also incurs a marketing cost to sell the product to consumers. If the retailer has $k \geq 0$ stores, each of which sells $x \geq 0$ units, total marketing cost is $S(k x)$, where $S(\cdot)$ increasing but concave. ${ }^{19}$ Combining the production and marketing components, the total input cost for a retailer selling $k x$ units is $\alpha k x+S(k x)$. The chain retailer simultaneously chooses its size (number of stores) and quantity (equivalently, price) in each location. Formally, it solves

$$
\begin{aligned}
\max _{k, x} & \pi(k, x)=k x(p(x)-\alpha)-S(k x)-\frac{c(k)}{\delta} \\
\text { subject to } & k \in[0, N] \\
& x \geq 0
\end{aligned}
$$

where $p(x)$ is the inverse demand function. The first constraint is on chain size, which must be nonnegative and cannot exceed the total number of locations in the economy. ${ }^{20}$ The second constraint is on the number of units sold per store, which cannot be negative.

The combination of economies and diseconomies of scale — declining marketing marginal cost, but increasing marginal cost of chaining - implies that, for a given value of $x$, the average cost per store is U-shaped. The standard results imply that the optimal choice of $k$ will be on the upward-sloping part of the average cost curve.

\footnotetext{
${ }^{18}$ Our analysis would not change if retailing technology involved two or more inputs, used in fixed proportions, if those inputs were supplied by competitive markets. We do, however, abstract from any cost advantages the chain may have in other inputs. For the types of products that Wal-Mart sells - apparel, footwear, furniture and fixtures - there is no systematic evidence of increasing returns to scale in production (Antweiler and Trefler, 2002).

${ }^{19}$ Formally, $S(0)=0, S^{\prime}>0, S^{\prime \prime}<0$, and $S^{\prime \prime \prime}>0$ so that marginal cost is declining in $k x$, but at a decreasing rate.

${ }^{20}$ For the most part, we assume that the upper limit $N$ on $k$ does not bind. This seems reasonable as a first approximation: although Wal-Mart currently has more than 3,000 stores in the U.S. alone, its expansion plan suggests there is plenty more room for it to grow. Wal-Mart's plans for 2006 include opening at least 140 new stores (Wal-Mart Stores, Inc., 2005). We also ignore integer problems in the solution $k^{*}$.
} 
Formally, an interior solution $\left(k^{*}, x^{*}\right)$ must satisfy the first-order conditions

$$
\begin{aligned}
& x \cdot\left(p(x)-\alpha-S^{\prime}(k x)\right)-\frac{c^{\prime}(k)}{\delta}=0 \\
& k \cdot\left(p^{\prime}(x) x+p(x)-\alpha-S^{\prime}(k x)\right)=0 .
\end{aligned}
$$

This interior solution dominates the corner solution $(k, x)=(0,0)$ if and only if it yields a positive profit. We show the second-order conditions for an interior solution and derive sufficient conditions for existence and uniqueness of the solution in Appendix A.

We write the solution to Equation $(2)$ as $k^{*}(x)$ and the solution to Equation (3) as $x^{*}(k)$. Figure 3 shows the determination of $x^{*}(k)$ at the intersection of the (downward-sloping) marginal cost and marginal revenue curves. Two marginal cost curves are represented as thin lines, each for a different value of chain size, $k$. Increasing $k$ rotates the marginal cost curve clockwise around $\alpha+S^{\prime}(0)$.

Figure 4 shows, for two different values of $\delta$, the simultaneous determination of $\left(k^{*}(x), x^{*}(k)\right)$. The curve $k^{*}(x)$, which depends on $\delta$, is shown as the thick solid line and $x^{*}(k)$ as the thin solid line. When $\delta$, the chain's technology parameter, is small, the cost of operating multiple stores is high. As $\delta$ increases, the curve $k^{*}(x ; \delta)$ rotates clockwise, increasing the optimal value of $k$. The new equilibrium features a higher $k^{*}$ as well as a higher $x^{*}$ : the chain operates more stores and sells more units per store (at a lower retail price). We formalize this in the following result:

Result 1 (Technological Change). The chain's size, units sold per store, total sales volume $(k x)$ and sales value $(k x p(x))$ all increase with $\delta$.

All proofs are in Appendix A.

There is much evidence that Wal-Mart's chaining technology has improved over time. In 1969, the company installed a computer in its first distribution center; by the late 1970s a computer network linked all Wal-Mart stores and distribution centers to company headquarters. Bar-code technology was added in all distribution centers by the late 1980s (Feiner, 
O'Andraia, Black, Jones, and Konik, 2002). If $\delta$ increases gradually, starting from a low level, chain size increases with it, and consumer prices fall.

\subsection{Foreign Production}

We now suppose that the consumption good can be manufactured either domestically or offshore (and imported) and derive both the conditions under which the chain chooses to import the good and the consequences of this choice.

Assume for simplicity that there are two possible production locations (domestic and foreign); we allow for a continuum of possible production locations in Section 3.5. In each location there is a large number of identical manufacturers with access to a constant-returns production technology, and pricing is competitive. We now write the domestic manufacturing sector's competitive price as $\alpha_{0}$. The foreign manufacturing sector has lower marginal production cost $\widetilde{\alpha}_{1} \ll \alpha_{0}$, but there is a transportation cost (normalized to zero for the domestically-produced good) and tariff that sum to $\tau$ per unit. We define $\alpha_{1} \equiv \widetilde{\alpha}_{1}+\tau<\alpha_{0}$ to be the marginal input cost if the good is produced offshore.

In addition to the production and transportation cost/tariff, the retailer must incur a fixed cost $F>0$ in order to purchase input from a foreign manufacturer. This fixed cost includes the cost of setting up a production facility or a relationship with a producer in a foreign country, or a network of buyers such as the one that Wal-Mart has in China, and possibly any non-pecuniary costs such as backlash from domestic residents. ${ }^{21}$ For now, we assume that the retailer, not the manufacturer, bears the cost $F$; we allow for the possibility that an intermediary pays the cost in Section 3.6. As mentioned earlier, approximately $50 \%$ of Wal-Mart's imports are direct imports through its contracts with foreign manufacturers.

\footnotetext{
${ }^{21}$ Swenson (2005) offers evidence from the U.S. Offshore Assembly Program (OAP) suggesting that the pattern OAP outsourcing is consistent with the presence of a fixed cost, which she attributes to search and product development.
} 
In these cases, it seems reasonable to assume that Wal-Mart bears any fixed cost. ${ }^{22}$

To capture the retailer's additional choice we introduce the variable $\theta \in\{0,1\}$, which equals 0 if the input is purchased from domestic producers and 1 if the input is imported. The chain's maximization problem becomes

$$
\begin{aligned}
\max _{k, x, \theta} & \pi(k, x, \theta)=k x\left(p(x)-(1-\theta) \alpha_{0}-\theta \alpha_{1}\right)-S(k x)-\frac{c(k)}{\delta}-\theta F \\
\text { subject to } & k \in[0, N] \\
& x \geq 0 \\
& \theta \in\{0,1\} .
\end{aligned}
$$

Since the choice of $\theta$ is discrete, to solve this problem the chain compares its maximized profit if it purchases the input from domestic suppliers with profit from the alternative case in which it purchases the input from foreign manufacturers. Letting $\left(k_{\theta}^{*}, x_{\theta}^{*}\right)$ be the conditional optimum $\left(k^{*}, x^{*}\right)$ for a given $\theta$, the chain compares $\pi\left(k_{0}^{*}, x_{0}^{*}, 0\right)$ and $\pi\left(k_{1}^{*}, x_{1}^{*}, 1\right)$; the choice of $\theta$ depends on whether the increase in profit from obtaining a lower-price input fully offsets the fixed cost of importing $F$.

The solution is shown graphically in Figure 5. An interior solution $\left(k_{0}^{*}, x_{0}^{*}\right)$ is shown at the intersection of the solid thick and thin curves representing $k_{0}^{*}(x ; \delta)$ and $x_{0}^{*}(k)$. The alternative solution $\left(k_{1}^{*}, x_{1}^{*}\right)$ is shown at the intersection of the dashed thick and thin lines. Because $\alpha_{1}<\alpha_{0}$, the chain earns a larger variable profit per store if the input is imported than if it is purchased domestically, so conditional on $\theta=1$ (and therefore a sunk cost $F$ ), for any level of sales per store $x>0$ the chain chooses a larger chain size $k^{*}(x)$. The curve $x^{*}(k)$ also depends on $\theta$, because the lower marginal cost associated with the imported product increases the value of $x$ at which marginal cost is equal to marginal revenue.

The following lemma formally establishes that the optimal chain size conditional on

\footnotetext{
${ }^{22}$ An estimated $40 \%$ of Wal-Mart's revenue comes from its private label brands (Petrovic and Hamilton, 2005).
} 
the chain purchasing input from offshore producers is larger than the optimal chain size conditional on its purchasing input from domestic producers.

Lemma 1. $k_{1}^{*} \geq k_{0}^{*}$, and $k_{1}^{*}>k_{0}^{*}$ except when $k_{0}^{*}=N$.

Let $\pi^{*}(\alpha, F, \delta)$ be optimized profit given parameters $(\alpha, F, \delta)$, and let

$$
G\left(\alpha_{1}, \delta\right) \equiv \pi^{*}\left(\alpha_{1}, 0, \delta\right)-\pi^{*}\left(\alpha_{0}, 0, \delta\right)
$$

be the difference, net of the fixed cost of importing $F$, between the chain's profit conditional on foreign sourcing (with the conditionally-optimal chain size $k_{1}^{*}$ selling the conditionallyoptimal number of units $x_{1}^{*}$ per store) and the chain's profit conditional on domestic sourcing (with the conditionally optimal chain having size $k_{0}^{*}$ with sales $x_{0}^{*}$ per store). Because $G(\cdot, \cdot)$ is the difference between the conditional optimized profits, net of $F$, it depends only on the parameters of the model and not on any decision variables. By the envelope theorem, $G>0$; the optimal input source is $\theta^{*}=1$ if and only if $G \geq F$.

\subsection{Technological Change and Trade Liberalization}

We can now analyze the effect of an improvement in the chain's technology (a rise in $\delta$ ) on imports. We continue to abstract from the technology-investment decision and treat the technology parameter $\delta$ as exogenous. The next result establishes that the decision to purchase input from offshore producers depends on $\delta$ : the chain only imports its input if its technological advantage is sufficiently large.

Result 2 (Technological Change). If $F$ is not too high, there exists some $\delta_{m}<\infty$ such that the chain purchases the input domestically when $\delta<\delta_{m}$ and imports the input once its chaining technology exceeds this level.

Result 2, combined with Result 1, implies that the chain grows with $\delta$ and chooses to import its input if $\delta$ is sufficiently high. Because we have only one good in this model, there is only one extensive margin, beyond which further increases in $\delta$ increase the chain's total 
sales and, therefore, total imports (on the intensive margin). With a continuum of goods with different parameter values, increases in $\delta$ would affect both the intensive and extensive margins of importing. By Lemma 1, the chain's size $(k$ and $x)$ increases discretely at $\delta=\delta_{m}$. We do not expect to see a discrete increase in the chain's size in the data, however, both because with many goods this effect would be muted and because in practice the chain's optimal size $k^{*}$ is constrained by real-world frictions such as "time to build" (Koeva, 2000). This result holds only if $F$ is not too large; if the fixed cost $F$ of importing is too high, the variable-cost savings from importing the input can never be justified. In that case, $\delta_{m}$ would be infinite and the input would be purchased domestically regardless the chain's technology level.

Result 2 is consistent with the experience of Wal-Mart in the late 1980s and early 1990s. Between 1985 and 1995, Wal-Mart's chaining technology improved dramatically with the introduction of "Retail Link," an innovative distribution system connecting its stores, distribution centers, headquarters and suppliers. Wal-Mart more than doubled in size over this period, transitioning from a regional chain with 745 stores in 20 states to a national chain with 2,200 stores in 49 states. And, at the same time, Wal-Mart launched, then retreated from, a massive "Buy American" campaign.

This result is also consistent with the simultaneous increase in U.S. Wal-Mart sales and U.S. imports from China, shown in Figure 1. Over the period 1984-2004, Wal-Mart's share of U.S. retail sales rose from $0.1 \%$ to $6.5 \%$; imports from China have grown at an even faster rate, and prices of clothes, toys and electronics - items increasingly imported from China and other LDCs - have fallen considerably. Apparel prices, for example, fell $82 \%$ relative to the overall price level between 1984 and 2004 and real toy prices fell $47 \%$ over this period.

Like technological change, trade liberalization affects both the extensive and intensive margins of the chain's importing decision. To analyze the effect of a reduction in tariffs on $k^{*}$ and $x^{*}$, we explicitly write the unit input cost of the imported good as $\widetilde{\alpha}_{1}+\tau$, with $\widetilde{\alpha}_{1}$ the production cost and $\tau$ the combined import tariff and transport cost. 
Result 3 (Trade Liberalization). If $F$ is not too high, there is some $\tau_{m}<\infty$ such that:

1. The chain purchases the input domestically when $\tau>\tau_{m}$ and imports the input once the tariff falls below this level;

2. $\tau_{m}$ is increasing in $\delta$;

3. For $\tau \leq \tau_{m}$, the chain's size, units sold per store, and total import volume and value all increase as $\tau$ declines.

This result is a consequence of the fixed cost of purchasing the input from offshore producers, which creates a threshold market size for offshore production. As the cost advantage of foreign producers increases (because of a decline in trade costs), the threshold market size declines. Improvements in the chain's technology increase its market size and raise the upper bound on trade barriers that can support trade. Once $\tau$ falls below this upper bound (at which point the chain begins to import and increases discretely in size), any further trade liberalization also increases the chain's size.

For $\tau \leq \tau_{m}$, we decompose the elasticity of total imports with respect to trade barriers as follows:

$$
\frac{d(k x)}{d \tau} \frac{\tau}{k x}=\frac{\partial x}{\partial \tau} \frac{\tau}{x}\left(1+\frac{\partial k}{\partial x} \frac{x}{k}\right)+\frac{\partial k}{\partial \tau} \frac{\tau}{k}\left(1+\frac{\partial x}{\partial k} \frac{k}{x}\right)
$$

This decomposition allows us to identify three distinct effects:

1. Demand Effect: $\frac{\partial x}{\partial \tau} \frac{\tau}{x}$. This is the "conventional" effect, which works through the increase in demand at a fixed number of locations due to lower unit cost.

2. Expansion Effect: $\frac{\partial k}{\partial \tau} \frac{\tau}{k}$. This effect works through the expansion of the chain. In our simple model, retailers in locations not served by the chain do not import at all, while the chain sells imported goods exclusively. More generally, as long as other retailers sell fewer imports than the chain, the expansion of the chain increases imports. We revisit this issue in Section 3.6. 
3. Scale Effect: $\left(\frac{\partial k}{\partial x} \frac{x}{k}\right) \frac{\partial x}{\partial \tau} \frac{\tau}{x}+\left(\frac{\partial x}{\partial k} \frac{k}{x}\right) \frac{\partial k}{\partial \tau} \frac{\tau}{k}$. As the chain expands, its marginal marketing cost falls, which further lowers its retail price and increases import, amplifying both the demand effect and the expansion effect.

All three of these effects work in the same direction. Together, they provide an alternative explanation for the "tariff elasticity puzzle" of Yi (2003). Yi argues that the response of trade volumes to tariff reductions over the past two decades implies an implausibly high price elasticity of demand. Here, the existence and expansion of the chain amplifies the demand effect. In Section 4, we quantify these effects and show that the demand effect accounts for approximately $43 \%$ of the total effect of a tariff reduction, the scale effect accounts for $32 \%$, and the remaining $25 \%$ is due to the expansion effect.

Because the direct effect of a tariff reduction on prices is amplified by the expansion and scale effects, consumer prices fall more than one-for-one with tariff reductions. Put differently, the wedge between the production cost and the retail price of a good, which is partly endogenous, falls as trade barriers are relaxed. Ironically, in our setting this price reduction occurs as the downstream sector - retailing — becomes more concentrated.

This decomposition also allows us to address what might be termed the "Fogel critique" to our model. Fogel argues that railroads were not as important as others had claimed, because canals would have appeared in their absence; one might similarly argue that in the absence of Wal-Mart (or another retail chain), a wholesaler could have taken advantage of the same economies of scale. ${ }^{23}$ But in the context of our model, while a wholesaler would benefit from the demand effect and the part of the scale effect that is an amplification of the demand effect, the expansion effect — and its amplification by economies of scale — would not be available to a wholesaler. Thus, the retail chain does something quite distinct from a wholesaler and brings a unique transmission mechanism to international trade.

A further amplification of the effect of tariffs on imports can arise through the chaining

\footnotetext{
${ }^{23}$ We model the intermediary's role explicitly in Section 3.6.
} 
technology, and in particular, through the interaction between trade liberalization and technological change. This channel provides a complementary mechanism through which a tariff reduction can have not only an amplified effect on imports, but one that increases over time, consistent with the observation that the relationship between tariff reductions and trade has become more pronounced over time.

As implied by Results 2 and 3, if $\delta$ is very low the chain purchases its input domestically regardless of $\tau$. As the chain's technology improves the range of values of $\tau$ for which the chain prefers foreign sourcing increases, and a small reduction in tariff is increasingly likely to shift the optimal input source from domestic to foreign manufacturers. Thus, the improvements in Wal-Mart's chaining technology and gradual reductions in tariffs may have worked together to bring about the large increase in Chinese imports observed in the 1990s. This technology-dependent tariff threshold can also explain why Wal-Mart is perceived to import not only more than stand-alone retailers, but also more than many smaller chains. Once $\tau$ falls below $\tau_{m}(\delta)$, further increases in $\delta$ increase imports continuously.

While our discussion has focused on the effect of a reduction in tariffs, the analysis applies equally to other cost reductions. An increasing share of international trade has shifted from ocean shipping, whose costs have been roughly constant since the 1950s, towards air transport, whose costs have declined sharply since the 1970s (Hummels, 1999). Combined, these trends imply a decline in average shipping costs, which will have the same effect as a decline in tariffs in our model. The analysis also applies to reductions in production costs. A decrease in the offshore production cost $\widetilde{\alpha}_{1}$, for example due to learning-by-doing or costreducing investment in human capital, induces chain expansion, which amplifies its effect on imports. A decrease in the value of the foreign currency (say, the yuan) which effectively reduces the dollar value of $\widetilde{\alpha}_{1}$ would also have the same effect. Many have argued in recent years that the yuan is undervalued. A revaluation of the yuan would, in our model, amount to an increase in $\alpha_{1}$ and would slow imports from China - by increasing their price and also by reducing the rate of Wal-Mart's expansion. 


\subsection{Induced Technical Change}

So far, we have treated $\delta$ as an exogenous parameter. In reality, however, a retailer has a choice of technology level. Wal-Mart chose to invest in computers in its early years, in the "Retail Link" software in the 1980s and 1990s, and more recently in RFID technology. Other chains, notably Target and Walgreen's, have made similarly large investments in their respective chaining technologies, especially in the past decade. We show below that endogenizing the retailer's technology level further amplifies the effect of lower trade barriers on imports.

To capture the retailer's technology choice, we assume that to achieve a technology level $\delta$, the retailer must invest an amount $I$ where $I(\delta)$ is increasing and convex in $\delta .{ }^{24}$ That is, where we have previously used $\delta$ as a primitive reflecting the chain's advantage over other retailers, now the function $I(\cdot)$ is the primitive: the retailer can use this investment function to achieve any level of chaining technology $\delta \geq 0$. To conserve on notation, we use the convention that if $k=0$ and $\delta=0, \frac{c^{\prime}(k)}{\delta}=0$.

The chain's maximization problem becomes

$$
\begin{aligned}
\max _{k, x, \theta, \delta} & \pi(k, x, \theta, \delta)=k x\left(p(x)-(1-\theta) \alpha_{0}-\theta \alpha_{1}\right)-S(k x)-\frac{c(k)}{\delta}-\theta F-I(\delta) \\
\text { subject to } & k \in[0, N] \\
& x \geq 0 \\
& \theta \in\{0,1\} \\
& \delta \geq 0 .
\end{aligned}
$$

The retail chain's choice of $\delta$ satisfies the condition

$$
\delta^{2} I^{\prime}(\delta)=c(k),
$$

\footnotetext{
${ }^{24}$ Formally, $I(0)=0, I^{\prime}>0, I^{\prime \prime}>0$.
} 
with the other first-order conditions unaffected. Assume that an interior solution exists; it is shown graphically in the $(k, \delta)$ plane in Figure 6 . The thick solid line $k^{*}\left(\delta ; \tau_{1}\right)$ is the solution, for $\tau=\tau_{1}$, to the simultaneous-equation problem $\left(x^{*}(k), k^{*}(x)\right)$, taking $\delta$ as given. The optimal chain size increases discretely at $\delta_{m}$ when the chain begins importing the input; for all other values of $\delta, k^{*}(\delta)$ is a smoothly increasing function. The thin curve $\delta^{*}(k)$ is the solution to Equation (6); it does not depend on either $\theta$ (the import decision) or $\tau$ directly.

The dotted line $k^{*}\left(\delta ; \tau_{2}\right)$ in Figure 6 shows how $k^{*}(\delta)$ responds to a reduction in tariff. The technology thresholds for importing, $\delta_{m}$, falls when $\tau$ falls; and $k^{*}(\delta ; \tau)$ increases for all values of $\delta \geq \delta_{m}$. As in the earlier analysis with exogenous $\delta$, a decrease in $\tau$ increases chain size. What is new here is that the effect on $k^{*}$ can be decomposed into two parts: holding $\delta$ fixed, there is an increase in $k^{*}(\delta)$, as explained above. In addition, because $\delta^{*}$ is an increasing function of $k$ a tariff reduction also leads to higher investment in chaining technology, which indirectly increases $k^{*}$ further. In other words, endogenizing the chain's technology level adds a fourth component to the effect of lower trade barriers (a reduction in $\tau$ ) on total imports.

There is a parallel between this effect and the result of "directed technical change" in recent models of endogenous technological change (see Acemoglu, 2002). Imports are an input of the chain retailer; as this input becomes cheaper the chain has an incentive to invest in technology that takes advantage of the cheaper input. In our context the technology takes the form of improvements in the organization and logistics of the chain, which complements the increasingly-abundant cheap imports.

\subsection{Product Cycle}

In this section we generalize our model by adding many potential production locations in order to analyze the relationship among trade policy, chain size, and the product cycle. We show that the product cycle — the migration of sourcing from one country to the next — 
is accelerated by the existence of the chain and adds another layer to the effect of a tariff reduction on import volume. ${ }^{25}$

Assume a continuum of possible production locations parameterized by its input cost $\alpha$ (inclusive of tariff) and let $F(\alpha)$ be the lowest possible fixed cost of importing from a location with marginal cost $\alpha$. We assume that $F$ is decreasing in $\alpha$ and that the domestic location is the only one where $F=0 .{ }^{26}$

The retail chain chooses the production location to maximize profit. We write the optimization problem as follows:

$$
\max _{\alpha} \quad G(\alpha, \delta)-F(\alpha)
$$

where $G(\cdot, \cdot)$ is defined in Equation (4) and the discrete variable $\theta$ is replaced by a continuous choice represented by $\alpha$.

The function $F(\alpha)$ is shown as the thick curve in Figure 7. We can also represent $G(\alpha ; \delta)$ in Figure 7. By construction, $G\left(\alpha_{0}, \delta\right) \equiv 0$ for all values of $\delta$. By the envelope theorem, $\frac{\partial G}{\partial \alpha}<0$ and $\frac{\partial G}{\partial \delta}>0$ for interior solutions when $\alpha<\alpha_{0}$, so $G(\alpha, \delta)$ is downward-sloping and becomes steeper, rotating clockwise about the point $\left(\alpha_{0}, 0\right)$, as $\delta$ increases.

In Figure 7 we show the curves $G(\alpha, \delta)$ for three different values of $\delta$, with $\delta_{1}<\delta_{2}<\delta_{3}$. The optimal choice of $\alpha$ for each value of $\delta$ (which is again treated as exogenous) is the point at which the vertical gap between the curves $G(\alpha, \delta)$ and $F(\alpha)$ is maximized. For low values of $\delta$, such as $\delta=\delta_{1}$, the optimum is point A: domestic production. When $\delta$ reaches a sufficiently high level, the retailer begins to source the good from a foreign location; at $\delta=\delta_{2}$, the retailer purchases input from the location denoted by point B. As the chaining technology improves further $\left(\delta=\delta_{3}\right)$, sourcing moves to another location denoted by point

\footnotetext{
${ }^{25}$ The product cycle usually refers to the process starting from a good's introduction in an industrialized country to the migration of its production, first to other industrialized countries and eventually to developing countries. Our context is one where the good is mature and so the product cycle here refers to the migration of production from one developing country to another.

${ }^{26}$ Formally, $F\left(\alpha_{0}\right)=0, F^{\prime}<0, F^{\prime \prime}>0, \lim _{\alpha \rightarrow 0} F(\alpha)=\infty$.
} 
C. Gereffi (1999) counts three major shifts of offshore apparel production since the 1950s: to Japan; to the "Big Three" Asian producers (Hong Kong, Taiwan, South Korea); and from the Big Three to China and a few other Southeast Asian countries (including Sri Lanka). There is also evidence that differently-sized U.S. retailers import from different countries and regions; see Gereffi (1994). In this sense, Wal-Mart's relationship with Chinese producers is quantitatively, but not necessarily qualitatively, different from the relationships other retailers have had, and continue to have, with other supplier countries.

We can also use Figure 7 to analyze the effect of a uniform tariff reduction. Suppose that all locations (except the domestic location) have the same tariff $\tau$ and redefine the horizontal axis of Figure 7 to be $\widetilde{\alpha}=\alpha-\tau$. The effect of a decrease in $\tau$ in this setting is similar to an increase in the chain's efficiency $\delta$. If the chain initially purchased the input from domestic producers (i.e., starting from point A), a uniform reduction in tariff would have the standard effect of moving production abroad; but if initial production were in a foreign location, such as B, a uniform tariff reduction would move the chain's optimal source to a different country, such as C. A uniform reduction in tariffs can therefore hurt some trading partners while helping others. This result could explain the empirical observation that China's share of U.S. imports has increased - and Latin America's has fallen — despite broadly similar tariff treatment in the 1980s and 1990s (see, e.g., Moreira, 2007). A high uniform tariff that applies to all non-domestic producers therefore protects not only domestic manufacturers, but also incumbent suppliers that are "close" to the domestic market on the $F(\alpha)$ locus. Also consistent with this view, Table 8 in Bernard, Jensen, and Schott (forthcoming) shows that the share of imports from low-, lower-middle, and upper-middle income countries has increased over the period $1993-2000 .{ }^{27}$

\footnotetext{
${ }^{27}$ The movement of industries across countries may be partially mitigated by the importance of physical distance. Moreira (2007) reports that from 1990-2002, over four per cent of world market share in manufacturing were lost to China from Brazil, the MERCOSUR countries, and the Andean countries compared to Mexico's loss of $0.3 \%$. Manufacturing in the East Asian countries lost $8.1 \%$ to China. Evans and Harrigan (2005) argue that for goods where timeliness matters, physical distance is paramount. They find that, from 1990-98, imports of "more-often-replenished" apparel goods to the U.S. grew more quickly for proximate
} 
Thus, a uniform reduction in tariff for all trading partners increases the chain's market size and moves the optimal input source to a country with lower unit costs, further increasing profit per store and inducing an additional increase in the size of the chain and sales per store. Endogenizing the chain's technology parameter $\delta$ in the presence of many potential production locations adds yet another effect of a tariff reduction on import volume. As in the previous section, a reduction in the tariff $\tau$ increases the chain's optimal choice of $\delta$. This, in turn, rotates the curve $G(\alpha, \delta)$ clockwise, moving the optimal source of input to a "farther" country - in other words, lowering the unit production cost $\widetilde{\alpha}$, which increases both the size of the chain and its sales per store.

This interaction between the level of tariff, $\tau$, and the cost of production, $\widetilde{\alpha}$, can have numerically large effects. With tariffs at the $5-10 \%$ range, a $1 \%$ reduction in tariff causes only a $0.05-0.1 \%$ in the total input cost. But if it lowers production cost even modestly, the overall effect on total input cost can be much larger because production cost accounts for the lion's share of the input cost. This channel, which we call the product-cycle (or sourcing) channel, becomes increasingly important as tariffs fall.

\subsection{Indirect Imports}

An assumption we have maintained so far is that the retailer makes the import decision and contracts directly with a low-cost overseas supplier. A direct, but unappealing and easily invalidated, implication of this assumption is that non-chain retailers do not sell any imported goods. The alternative specification described in this section allows for the presence of an intermediary importer or merchandising firm, which purchases the product from producers in the foreign location (incurring a cost $F$ to do so) and sells it to any demanding retailer at a markup.

Several aspects of the legal and institutional arrangements matter here. First, we as-

countries like Mexico than far-away countries like China, implying that for some industries, the importance of physical distance may dominate the effect discussed in this section. 
sume that the intermediary can price discriminate among different retailers. This greatly simplifies the problem, because we can focus on the price the intermediary charges the chain retailer independently of the prices it charges other retailers, allowing us to continue to abstract from the structure of the rest of the market. This assumption could not hold if the intermediary were bound by the Robinson-Patman Act of 1936, which forbids price discrimination "between different purchasers of commodities of like grade and quality [...] where the effect of such discrimination may be substantially to lessen competition or tend to create a monopoly in any line of commerce." The Act allows for prices to vary with the "grade or quality" of the product, however, so we are implicitly assuming that the product is easily modifiable in ways that make the Act's provisions non-binding. Small household appliances, such as coffee makers and toaster ovens, are ready examples of products with a large array of easily adjustable features.

A second important assumption we make is that the intermediary possesses all the market power and can charge the retail chain its reservation price. In terms of timing, this is equivalent to assuming that the intermediary sets prices first and the retailer can buy as much (or as little) from it as it wants at the announced price. Importantly, we assume that the retail chain chooses $x$ and $k$ after it observes the intermediary's price, and the intermediary anticipates this choice. ${ }^{28}$

Finally, we assume that the retail chain also has the option of importing directly by duplicating the fixed cost $F$. This determines the outside option of the chain, which we assume is binding for the intermediary. The markup the intermediary charges the retail chain, denoted $m$, is therefore determined by the identity

$$
\pi^{*}\left(\alpha_{1}+m, 0, \delta\right) \equiv \pi^{*}\left(\alpha_{1}, F, \delta\right)
$$

\footnotetext{
${ }^{28}$ An alternative in which bargaining power is shared between the two players generates the same qualitative results as the case we consider.
} 
where, as before $\pi^{*}(\alpha, F, \delta)$ is optimized profit given parameters $(\alpha, F, \delta)$.

The following result establishes some properties of the intermediary's markup.

Result 4 (Intermediary's Markup). The intermediary's markup satisfies:

1. $m>0$;

2. For $\delta \geq \delta_{m}, m$ is decreasing in $\delta$;

3. For $\tau \leq \tau_{m}, m$ is increasing in $\tau$.

Part 1 of Result 4 is due to the fact that by saving the retailer the fixed investment, $F$, the intermediary can charge the retailer a higher price while holding its profit constant. While the chain's profit is the same under both direct and indirect imports (by the assumptions that the intermediary possesses all the market power and that the price constraint is binding), the fact that marginal cost is different under direct and indirect importing implies that the retailer's size and prices will not be the same. Specifically, direct imports would result in a larger retail chain and lower consumer prices.

The intuition for Part 2 of Result 4 is that an exogenous increase in $\delta$ increases the profit the chain can earn from direct imports. To stay indifferent between direct and indirect imports the chain's profit from indirect imports must also increase. This is achieved by lowering the markup charged by the intermediary.

This result is consistent with anecdotal evidence that the price Wal-Mart pays suppliers has fallen as the chain has grown and is lower than the price other buyers pay. Fishman (2006), for example, cites claims by manufacturers of "consistent, irresistible requests" for annual price cuts (p. 77). In our view, what makes the requests "irresistible" is the fact that the intermediary makes a larger profit by acquiescing than it would by refusing - because to refuse is to induce the chain to start importing directly. Such a switch by the chain would reduce the intermediary's profit for two reasons. First, it would lose the markup it could have earned on all sales to the chain. Second, because the chain would expand if it were 
to face a marginal cost of $\alpha_{1}$ instead of $\alpha_{1}+m$, the number of other retailers to which the intermediary could sell would fall as well. This result is also consistent with a study reported by Riper (2007) finding that suppliers' gross margins are inversely related to the fraction of their output sold to Wal-Mart and that very few companies that earn at least $10 \%$ of their revenue from Wal-Mart achieve their sector's average gross margin.

The intuition for Part 3 of Result 4 is that a reduction in tariff that increases the profitability of direct imports would lead the chain to expand if it imported directly, increasing its profit above and beyond the increase that would come from the cost reduction alone. To keep the chain from exercising this option, the intermediary must offer the chain lower price that similarly increases its profit.

This result implies that tariff reductions can affect yet another wedge, that of the double marginalization. In the presence of a monopolist intermediary, a tariff reduction that increases the profitability of direct imports forces the intermediary to lower the markup it charges the chain, further amplifying the effect of trade liberalization on the chain's imports. Since the price the chain faces, and consequently also the price that it sets for consumers, is lower than the price of other retailers, the expansion of the chain increases imports even if small retailers are also selling imported goods.

This discussion has sidestepped the more complicated problem that the intermediary would face if the Robinson-Patman provisions were binding. In that case we could not solve for the price the intermediary charges one retailer separately from the price it charges other retailers. In the extreme case, it may have to supply a large chain retailer and many singlestore retailers at the same price. This scenario is interesting because it could explain some of the dynamics we observe in the retail sector. As long as the price constraint imposed by the chain retailer is not too low — that is, as long as $\delta$ is not too high — the intermediary may find it profitable to sell to both constituencies at a markup $m$. Once $\delta$ increases beyond some threshold, however, the intermediary may prefer to set a higher price, increasing the markup it receives from small retailers, despite the fact that this would mean losing the 
chain as a customer.

\section{Numerical Exercise}

Our model identifies three main channels through which exogenous changes such as tariff reductions and technology improvements affect the size of the chain retailer. In this section, we compare these three effects — the demand effect, expansion effect, and scale effect — quantitatively. The exercise is constrained by the limits of the data but the calculations allow us to use the model to (1) assess the importance of scale economies of the retail chain in amplifying effects from exogenous shocks, (2) derive a nonlinear relationship between input cost and the sales volume of the chain, and (3) decompose the growth of Wal-Mart from 1984 to 2004 into that which is attributable to technology improvements and that which is attributable to reductions in trade barriers and resultant changes in product sourcing. We find that the demand effect accounts for approximately $43 \%$ of the full effect of a tariff reduction on sales volume; chain scale economies and increase in the number of stores account for the remaining $57 \%$. Increases in the efficiency of Wal-Mart's chaining technology account for approximately $60 \%$ of the increase in sales volume. The remaining changes are due to decreases in input cost which include exogenous reductions in tariff and endogenous reductions due to changes in sourcing choices and intermediary markups.

\subsection{Method and Parameter Estimates}

For this numerical exercise, we use the following functional forms:

$$
\begin{aligned}
p(x) & =A x^{-\frac{1}{\varepsilon}}, \quad A>0, \varepsilon>1 \\
\frac{c(k)}{\delta} & =\frac{k^{2}}{2 \delta} \\
S(k x) & =s(k x)^{\sigma}, \quad s>0, \sigma \in(0,1) .
\end{aligned}
$$


The first-order conditions for $k$ and $x$, respectively, are:

$$
\begin{array}{r}
x \cdot\left(A x^{-\frac{1}{\varepsilon}}-\alpha-s \sigma(k x)^{\sigma-1}\right)-\frac{k}{\delta}=0 \\
\frac{\varepsilon-1}{\varepsilon} \cdot A x^{-\frac{1}{\varepsilon}}-\alpha-s \sigma(k x)^{\sigma-1}=0,
\end{array}
$$

where $\alpha$ here denotes the marginal input cost, inclusive of transportation cost and tariff (applicable if the good is imported).

To obtain numerical values for the parameters in the model, we use information from Wal-Mart's 1995 Annual Report. Wal-Mart's fiscal year ends January 31, so the 1995 annual report contains information most relevant to the calendar year 1994. All dollar values are in 1994 dollars unless stated otherwise. We normalize $\alpha$ to one in 1994 and set the marketing economies-of-scale parameter $\sigma=0.8$ (we report some results for different values of $\sigma$ ). The number of Wal-Mart stores, $k$, and revenue per store, $p \cdot x$ (calculated as total revenue divided by number of stores) are 2,833 and $\$ 29,115,425$, respectively.

Wal-Mart also reports an expenditure of $\$ 12,858$ million on "operating, sales, and general administration" (OSGA), which we interpret as its chaining cost; using Equation (9) we can infer $\delta$. Combining this value with the relationship $\varepsilon=\frac{p x \delta}{k}$ (derived from the two first-order conditions) allows us to compute $\varepsilon$.

Wal-Mart reports its "cost of sales" to be $\$ 65,586$ million, which we interpret as the sum of input cost and marketing cost. Combining this accounting relationship and Equation (12) allows us to solve simultaneously for $k x$ and $s$. We divide $k x$ by $k$ to solve for $x$ and combine with the known value $p x$ to solve for $p$. We then use the demand equation, Equation (8), to solve for $A$. Table 3 summarizes our parameters calculated from the 1994 data.

We calculate the demand elasticity, $\varepsilon$, to be 3.2 . This number is broadly consistent with estimated price elasticities for various food categories at Dominick's Finer Foods grocery stores reported by Chevalier, Kashyap, and Rossi (2003), which ranged from 1.2 to 5.7, with a median of 2.2, and with an estimate by Chiou (2005) putting the price elasticity of demand 
for DVDs at Wal-Mart around 2. We expect the aggregate price elasticity of demand to be higher than elasticities of demand for specific categories of goods in the presence of demand for "one-stop shopping": a reduction in the price of one good generates additional demand for other goods sold at the store by increasing the number of people who shop there (see Basker, Klimek, and Van, 2008, for a discussion on the relationship between retail chain size and scope).

\subsection{Quantitative Elasticity Decomposition}

In our model, the expansion of the retail chain and the chain's scale economies augment the conventional demand price response to shocks such as a reduction in tariff. Using the parameters we estimated above, we can quantify these three effects: the demand effect, expansion effect, and scale effect - through which tariff reductions affect Wal-Mart's sales volume. We quantify these three effects as elasticities as shown in equation (5) by implicitly differentiating Equations (11) and (12). We evaluate these quantities using 1994 values of relevant variables. For $\tau$, we use a specific tariff + transport cost of $\tau=0.0967 .^{29}$

We report these results in Table 4 . For $\sigma=0.8$, the elasticity of imports with respect to tariff is approximately -5 ; that is, a $1 \%$ reduction in tariff causes a $5 \%$ increase in import volume. Of this amount, approximately $43 \%$, or -2.2 , is due to the demand effect; $25 \%$ $(-1.3)$ is due to the expansion effect, and $32 \%(-2.1)$ is due to the scale effect. For lower values of $\sigma$, stronger scale economies for the chain, the higher is the total tariff elasticity of imports. ${ }^{30}$ But while the absolute values of the three effects depend on the choice of $\sigma$,

\footnotetext{
${ }^{29}$ Hummels (1999) estimates transportation cost in 1995 at $4.37 \%$ of the value of goods. For the relevant $a d-$ valorem tariff rate, we use the average (unweighted) tariff rate charged by the U.S. to Normal Trade Relations countries in 1994 from the U.S. International Trade Commission (USITC), averaged over all products with the exception of live animals, fresh produce, nuclear reactors, aircraft, railroad cars, and vessels and parts, from http://reportweb.usitc.gov/tariff/tariff_form_.jsp, which is approximately $6.33 \%$. The sum of the two is $10.7 \%$. Given the normalization $\alpha_{1}=\widetilde{\alpha}_{1}+\tau=1$, this implies that $\tau=0.0967$.

${ }^{30} \mathrm{As} \sigma$ approaches 0.87 , a singularity problem increases $s$ and reduces all three effects sharply towards zero.
} 
the demand effect's share of the total elasticity is quite stable around $43-45 \%$. Thus, the existence of the chain more than doubles the effect of a tariff reduction on import volume.

\subsection{Changes over Time}

A combination of tariff reductions, sourcing changes, and possibly markup reductions has reduced the marginal input cost, $\alpha$, over time. Our model predicts a non-linear relationship between $\alpha$ and the size of the retail chain. This nonlinear relationship is shown in Figure 8, which plots the results of numerical simulations that hold $\delta$ fixed at the 1994 value and allow $\alpha$ to vary between the values 0.7 and 1.3 . Small decreases in the marginal input cost, $\alpha$, have a much larger impact on total output when $\alpha$ is small than when it is large.

We next calculate the empirical reduction in $\alpha$ between 1984 and 2004. To do this, we calculate $\delta_{t}$ for $t=1984$ and 2004 from the relationship (derived from first-order conditions) $\delta_{t}=\frac{\varepsilon \cdot k_{t}}{p_{t} \cdot x_{t}}$ where $\left(p_{t} \cdot x_{t}\right)$ and $k_{t}$ are actual revenue per store (in 1994 dollars) and number of stores, respectively, in year $t$, and $\varepsilon=3.2075$ is the elasticity derived above. This formula implies that $\delta_{1984}=0.000201$ and $\delta_{2004}=0.000401$; by way of comparison, the 1994 value of $\delta$ was $0.000312 .{ }^{31}$ We derive $x_{t}$ and $p_{t}$ from actual value of $p_{t} \cdot x_{t}$ (converted to 1994 dollars) using the demand equation. Finally, we calculate $\alpha_{t}$ as the value of $\alpha$ for which the first-order condition for $k$, Equation (11), is satisfied.

These calculations are summarized in Table 5. The cost of input (inclusive of relevant tariffs and transportation cost, as well as intermediary markup), $\alpha$, fell by $23 \%$ of the period 1984-2004 (from 1.176 to 0.930), with most of the decline occurring in the first half of the period (recall that the 1994 value of $\alpha$ is normalized to 1 ).

According to this calculation, the real price charged to consumers, $p$, fell by $57 \%$ over this 20-year period. As a comparison, while the CPI for all items rose $66 \%$ during this time, the CPI for clocks, lamps, and decorative items rose by only $11 \%$, a $55 \%$ drop in real terms.

\footnotetext{
${ }^{31}$ If we derived $\delta_{t}$ from Wal-Mart's reports of OSGA expenses for these years instead, we would have gotten $\delta_{1984}=0.000169$ and $\delta_{2004}=0.000473$.
} 
Real apparel prices fell by $82 \%$, the price of household furnishings fell by $86 \%$, the price of furniture and bedding by $88 \%$, and the price of toys by $47 \%$.

To get a sense of the relative contributions of the decline in $\alpha$ and the rise in $\delta$ to the changes in $(k x)$ over the period 1984-2004, we decompose this change as

$$
\frac{\Delta(k x)}{k x}=\left(\frac{\partial(k x)}{\partial \delta} \frac{\delta}{k x}\right) \frac{\Delta \delta}{\delta}+\left(\frac{\partial(k x)}{\partial \alpha} \frac{\alpha}{k x}\right) \frac{\Delta \alpha}{\alpha}
$$

where $\frac{\Delta(k x)}{k x}$ is approximated using the log change in $(k x)$ from 1984 to 2004 and similarly for the other variables ( $\alpha$ and $\delta$ ). We do not distinguish here between reductions in the cost of production $\widetilde{\alpha}$ and reductions in the tariff (or transportation cost) $\tau$, for several reasons. First, at the beginning of the period (before Wal-Mart's launch of the "Buy American" campaign) Wal-Mart's imports were probably minimal; only after tariff rates fell below some threshold level, $\tau_{m}$, did the tariff rate become meaningful (Result 3). Moreover, at $\tau=\tau_{m}$ the increase in $(k x)$ is discrete, due to a decrease in $\widetilde{\alpha}$, the cost of production, when the retailer switches from domestic to foreign sourcing. Even after switching to foreign production, $\alpha$ may decrease more than one-for-one with tariff reductions as the optimal location of production moves, and/or as the markup, $m$, charged by an intermediary decreases. Available data do not allow us to distinguish between these channels, and we do not have estimates of transport cost for years other than 1995.

The decomposition is reported in the last row of Table 6 . The increase in $\delta$ over this period accounts for approximately $59 \%$ of the total increase in $k x$, and the decrease in $\alpha$ accounts for $41 \%$ of this increase. ${ }^{32}$

As above, we can further decompose each term into a demand channel, an expansion

\footnotetext{
${ }^{32} \mathrm{As}$ an alternative approach, we performed a counterfactual exercise in which we held $\alpha$ constant at 1 and let $\delta$ change from its 1984 level to its 2004 level. This exercise generated $59.4 \%$ of the actual increase in $(k x)$ over this period, consistent with this conclusion.
} 
channel, and a scale channel:

$$
\begin{aligned}
& \frac{\partial(k x)}{\partial \delta} \frac{\delta}{k x}=\underbrace{\frac{\partial k}{\partial \delta} \frac{\delta}{k}}_{E E_{\delta}}+\underbrace{\frac{\partial x}{\partial \delta} \frac{\phi^{0}}{x}}_{\partial E_{\delta}}+\underbrace{\left(\frac{\partial x}{\partial k} \frac{k}{x}\right) \frac{\partial k}{\partial \delta} \frac{\delta}{k}+\left(\frac{\partial k}{\partial x} \frac{x}{k}\right) \frac{\partial x}{\partial \delta} \frac{\delta}{x}}_{S E_{\delta}} \\
& \frac{\partial(k x)}{\partial \alpha} \frac{\alpha}{k x}=\underbrace{\frac{\partial k}{\partial \alpha} \frac{\alpha}{k}}_{E E_{\alpha}}+\underbrace{\frac{\partial x}{\partial \alpha} \frac{\alpha}{x}}_{D E_{\alpha}}+\underbrace{\left(\frac{\partial x}{\partial k} \frac{k}{x}\right) \frac{\partial k}{\partial \alpha} \frac{\alpha}{k}+\left(\frac{\partial k}{\partial x} \frac{x}{k}\right) \frac{\partial x}{\partial \alpha} \frac{\alpha}{x}}_{S E_{\alpha}}
\end{aligned}
$$

The first three rows of Table 6 report the relative contribution of each effect (elasticities are evaluated at their 1994 levels). The demand effect, which comes entirely from decreases in $\alpha$, explains $17.6 \%$ of the total increase in $(k x)$ over this period. The effects introduced by the retail chain account for the remaining $82.4 \%$ of the increase in $(k x)$ with the expansion effect contributing $45.5 \%$ and the scale effect $36.8 \%$.

\section{Concluding Remarks}

Our goal in this paper has been to suggest a link between recent trends in the U.S. retail sector and trends in imports of consumer goods to the U.S. We show that the interaction between scale economies in the retail sector and scale economies in the import process generates a two-way relationship between import volume and chain size; this interaction has implications for trade volume and the sensitivity of imports to tariff reductions. Technological innovations in the retail sector increase chain size and, by increasing market size, also increase imports. Likewise, reductions in the cost of merchandise (due, for example, to tariff reductions or foreign currency devaluations) increase both imports and the size of the dominant retailer. When the retailer's level of investment in the chaining technology is endogenized, we obtain a result akin to "directed technical change" in that the retailer's investment in chaining technology increases as imports become cheaper and more abundant.

Many observers (e.g., McKinsey Global Institute, 2001) have noted the retail sector's high productivity growth rate in the 1990s and cite Wal-Mart as an important source of 
this productivity increase. Calculations based on our model suggest that about $60 \%$ of Wal-Mart's growth from 1984-2004 is directly attributable to technology advances. The remaining $40 \%$ comes from reductions in input cost, including include tariff reductions as well sourcing from lower cost producers. It is likely that all these cost saving factors contribute to the observed productivity growth in retail and Wal-Mart in particular.

While our discussion has centered on the effect of a decline in tariffs on chain size and import volume, the feedback effect the chain exerts on imports is also present when foreign production costs fall. Any decline in the cost of production in China, for example due to investment in human or physical capital, relaxation of regulation, or learning, increases the optimal size of the retail chain and so increases imports not only through the direct demand effect but also by expanding the chain and its level of investment in "chaining" technology.

Our model abstracts from competition between chains to highlight the effect of increasing returns on imports, input cost, and technology adoption for a single chain. We hope future research will examine the extent to which the partial-equilibrium implications of our analysis carry through to a setting with endogenous market structure and the interaction between the present complementarities and strategic considerations. If markets are contestable, retail prices will be driven down, reducing the marginal return to an additional store. ${ }^{33}$ At the same time, the return to lower costs that come with an expanded chain - due to returns to scale and cheaper sourcing - may be higher if the retailer can thereby "shake off" the competition. The resulting equilibrium may have a number of small, symmetric, chains, or, in the spirit of Bagwell, Ramey, and Spulber (1997), an asymmetric distribution in which one chain makes a larger investment in size and dominates the market.

The implications of our model extend to a situation with many goods or industries. Suppose that the chain retailer sells many goods, which vary with respect to the gap in unit production costs between domestic and foreign manufacturers. This variable gap may

\footnotetext{
${ }^{33}$ In an earlier version of this paper, Basker and Van (2006), we allowed for contestable markets, but potential entrants were stand-alone stores with relatively high cost.
} 
reflect different degrees of "maturity" of the goods. When the chain is small, only goods for which the gap in unit production cost is sufficiently large are produced offshore, with the remaining goods produced domestically. As the chain expands - e.g., in response to trade liberalization — more and more products are sourced offshore. The offshoring of each good creates a "wake" as it leads the chain to expand and increases the benefit of offshoring additional goods. This interpretation allows reductions in the tariff, $\tau$, to affect unit input cost, $\alpha$, continuously even if there is just one foreign production location. It is also consistent with the observation by Ruhl (2008) that the response of the extensive margin to a tariff reduction can be much larger than response of the intensive margin. The importance of the extensive margin is also underscored by Bernard, Jensen, and Schott's (forthcoming) finding that firms that import multiple unique products employ more workers than firms that import just one product and import more (in dollar terms) per worker. In this framework as well, the pace of offshoring is directly related to the response of chain size to trade liberalization, which, as before, depends on the chain's technology.

In conclusion, we note that our model highlights a mechanism not usually mentioned in popular discourse. There is a common perception that Wal-Mart and trade with China are related. But the discussion of the relationship between Wal-Mart's growth and import growth tends to focus on Wal-Mart's monopsony power implied in the often-made claim that WalMart "forces" suppliers to move production overseas in order to cut costs. In a model with increasing marginal cost, a monopsonist who cannot price-discriminate depresses production to extract a lower input price. Such a model counter-intuitively implies that in the absence of Wal-Mart and other large chains, imports would have grown at a rate even faster than the one we have observed over the past two decades. While we do not deny the importance of issues arising from Wal-Mart's market power beyond its role as seller, discussions of such issues are taking place without the benefit of formal analysis. Our model is a starting point from which to bring economic analysis into the debate surrounding Wal-Mart's role in an increasingly-globalized setting. 


\section{A Proofs}

Existence of Equilibrium. Assume that only domestic production is possible. The chain retailer solves the following problem

$$
\begin{aligned}
\max _{k, x} & \pi(k, x)=k x(p(x)-\alpha)-S(k x)-\frac{c(k)}{\delta} \\
\text { subject to } & k \in[0, N] \\
& x \geq 0
\end{aligned}
$$

where

As noted in the text (Section 3.1), the corner solution $(k, x)=(0,0)$ guarantees zero profit for all $\delta>0$. If an interior solution $\left(k^{*}, x^{*}\right)$ exists, it must satisfy the first-order conditions

$$
\begin{aligned}
& x \cdot\left(p(x)-\alpha-S^{\prime}(k x)\right)-\frac{c^{\prime}(k)}{\delta}=0 \\
& k \cdot\left(p^{\prime}(x) x+p(x)-\alpha-S^{\prime}(k x)\right)=0,
\end{aligned}
$$

along with second-order conditions. Graphically, this solution is the intersection of $x^{*}(k)$ and $k^{*}(x)$ in Figure 4 .

The second-order conditions are derived from the condition that the Hessian matrix is negative semi-definite:

$$
\begin{aligned}
\pi_{x x}= & k\left(p^{\prime \prime}(x) x+2 p^{\prime}(x)-k S^{\prime \prime}(k x)\right)<0 \\
\pi_{k k}= & -\left(x^{2} S^{\prime \prime}(k x)+\frac{c^{\prime \prime}(k)}{\delta}\right)<0 \\
\pi_{x x} \pi_{k k}-\pi_{k x}^{2}= & -k\left(p^{\prime \prime}(x) x+2 p^{\prime}(x)-k S^{\prime \prime}(k x)\right)\left(\left(x^{2} S^{\prime \prime}(k x)+\frac{c^{\prime \prime}(k)}{\delta}\right)\right. \\
& -\left(p^{\prime}(x) x+p(x)-\alpha-S^{\prime}(k x)-k x S^{\prime \prime}(k x)\right)^{2}>0 .
\end{aligned}
$$


One way to interpret these conditions is as a set of restrictions on the magnitude of $S^{\prime \prime}(\cdot)$, or the degree of increasing-returns in the chain's marketing technology. The marketing component of marginal cost, $S^{\prime}(k x)$, falls when either $k$ or $x$ increases; an interior optimum can only exist if it does not fall too rapidly. Equation (18) bounds the extent of increasing returns due to increasing $x$ relative to the decline in marginal revenue from increasing $x$, holding $k$ constant. Equation (19) bounds the extent of increasing returns due to increasing $k$ (now holding $x$ constant) relative to the increased chaining cost entailed in increasing $k$. Equation (20) bounds the extent of increasing returns when $x$ and $k$ are allowed to co-vary. Since $x$ and $k$ move together (see below), for some functional-form assumptions this condition is sufficient and implies the previous two.

An interior intersection of $k^{*}(x)$ and $x^{*}(k)$ occurs if:

1. $x^{*}(0) \geq k^{*-1}(0)$, that is, if the $x$-intercept of $x^{*}(k)$ is weakly above the $x$-intercept of $k^{*}(x)$;

2. $\frac{d x^{*}(k)}{d k}>0, \frac{d k^{*}(x)}{d x}>0$ over all the relevant range; and

3. $\frac{1}{d k^{*}(x) / d x}>\frac{d x^{*}(k)}{d k}$.

To see that the first condition is satisfied, from Equation (17), note that for $k=0, x^{*}$ is undefined but nonnegative; and from Equation (16), for $x=0, k^{*}=0$. For the second condition, differentiate the two first-order conditions to get:

$$
\begin{aligned}
\frac{d k^{*}(x)}{d x} & =\frac{\pi_{x} / k-k x S^{\prime \prime}(k x)}{-\pi_{k k}} \\
\frac{d x^{*}(k)}{d k} & =\frac{x S^{\prime \prime}(k x)}{\pi_{x x} / k} .
\end{aligned}
$$

The denominator of Equation (21) is positive by second-order condition (19). For $x<x^{*}(k)$, $\pi_{x}>0$ so the numerator is also positive and $\frac{d k^{*}(x)}{d x}>0$. For $x>x^{*}(k), \pi_{x}<0$, but in the neighborhood of $x^{*}, \pi_{x}$ is not too negative, so the numerator remains positive. As $x$ increases beyond some level, $\pi_{x}$ becomes sufficiently negative that $\frac{d k^{*}(x)}{d x}$ turns negative. 
By the second-order condition (18) and concavity of $S(\cdot)$, both the numerator and the denominator of Equation (22) are negative, so $\frac{d x^{*}(k)}{d k}>0$.

The third condition, $\frac{1}{d k^{*}(x) / d x}>\frac{d x^{*}(k)}{d k}$, can be written explicitly as

$$
\frac{-\pi_{k k}}{\pi_{x} / k-k x S^{\prime \prime}(k x)}>\frac{x S^{\prime \prime}(k x)}{\pi_{x x} / k}
$$

and, after some algebraic manipulation, as

$$
\pi_{x x} \pi_{k k}-\left(\frac{\pi_{x}}{k}-k x S^{\prime \prime}(k x)\right)^{2}>\left(k x S^{\prime \prime}(k x)-\frac{\pi_{x}}{k}\right) \frac{\pi_{x}}{k} .
$$

The term on the left-hand side is positive by second-order condition (20). The right-hand side is negative for $x<x^{*}(k)$, equals zero at $x=x^{*}(k)$ and turns positive for $x>x^{*}(k)$. As above, in the neighborhood of $x^{*}$ the RHS term is not too positive, so the inequality holds.

The proof of existence of equilibrium when foreign sourcing is allowed follows analogously.

Proof of Lemma 1. Define $\Gamma_{\theta}(k)$ to be the marginal benefit of expanding the chain conditional on an input source $\theta \in\{0,1\}$ and choosing the optimal number of units to sell in each of the chain's locations, $x_{\theta}^{*}(k)$ :

$$
\begin{aligned}
\Gamma_{\theta}(k) & \equiv \frac{d}{d k}\left(\pi\left(k, x_{\theta}^{*}(k), \theta\right)+\frac{c^{\prime}(k)}{\delta}\right) \\
& =x_{\theta}^{*}(k)\left(p\left(x_{\theta}^{*}(k)\right)-(1-\theta) \alpha_{0}-\theta \alpha_{1}-S^{\prime}\left(k \cdot x_{\theta}^{*}(k)\right)\right)
\end{aligned}
$$

An interior solution $k_{\theta}^{*}$ - denoting the optimal chain size conditional on the input source - equates $\Gamma_{\theta}(k)$ with the marginal cost of expanding the chain, $\frac{c^{\prime}(k)}{\delta}$. Since the marginal cost of chain expansion is increasing in $k$, for interior solutions it is sufficient to show that $\Gamma_{1}(k)>\Gamma_{0}(k)$.

By the envelope theorem, $\frac{d \pi}{d \alpha}=\frac{d \Gamma}{d \alpha}=-x_{\theta}^{*}(k)$. Since the first-order condition (3) implies 
that $x_{1}^{*}(k)>x_{0}^{*}(k)$ in the unconstrained optimization problem, $\Gamma_{1}(k)>\Gamma_{0}(k)$, and $k_{1}^{*}>k_{0}^{*}$ for all interior $k_{0}^{*}$.

Finally, since $k_{1}^{*}>1$ for all $x>0$, but $k_{0}^{*}=1$ for $x \leq x_{s}$, and since $x^{*}(k)>0$ regardless of $\theta$, whenever $k_{0}^{*}=1$ then $k_{1}^{*}>1$. Also, since $N$ is the upper bound for chain size, whenever $k_{0}^{*}=N$ then $k_{1}^{*}=N$.

Proof of Result 2. To conserve on notation, we write $G(\delta)$ taking $\alpha_{1}$ as a constant. We need to show that there is some value $\delta_{m}<\infty$ such that $F>G(\delta)$ for $\delta<\delta_{m}$ and $F<G(\delta)$ for $\delta>\delta_{m}$.

For values of $\delta$ such that $k_{1}^{*}(\delta)<N, \frac{d G}{d \delta}=\frac{c\left(k_{1}^{*}\right)-c\left(k_{0}^{*}\right)}{\delta^{2}}>0$ (by the envelope theorem and Lemma 1), so the benefit of importing increases with the firm's technology parameter (for interior values of $k$ ). Also, for values of $\delta$ such that $k_{1}^{*}(\delta)=N$ but $k_{0}^{*}(\delta)<N$, by the envelope theorem $\frac{d G}{d \delta}=\frac{c(N)}{\delta^{2}}+\frac{c^{\prime}\left(k_{0}^{*}\right)}{\delta} \frac{d k_{0}^{*}}{d \delta}$, which is also positive (since we have already shown that $\left.\frac{d k_{0}^{*}}{d \delta}>0\right)$. For values of $\delta$ such that $k_{0}^{*}(\delta)=k_{1}^{*}(\delta)=N, \frac{d G}{d \delta}=0$. Define

$$
\delta_{N} \equiv \min \left\{\delta: k_{0}^{*}(\delta)=N\right\}
$$

Since $\delta_{m}$ is defined by $G\left(\delta_{m}\right)=F$, such a threshold exists if $F<G\left(\delta_{N}\right)$.

Proof of Results 3.1 and 3.2. We need to show that there is some value $\tau_{m}<\infty$ such that $F>G\left(\widetilde{\alpha}_{1}+\tau, \delta\right)$ for $\tau>\tau_{m}$ and $F<G\left(\widetilde{\alpha}_{1}+\tau, \delta\right)$ for $\tau<\tau_{m}$.

By construction, $G\left(\widetilde{\alpha}_{1}+\tau, \delta\right)$ is positive whenever $\tau<\alpha_{0}-\widetilde{\alpha}_{1}$, which holds by assumption; and $\lim _{\tau \rightarrow\left(\alpha_{0}-\widetilde{\alpha}_{1}\right)} G\left(\widetilde{\alpha}_{1}+\tau, \delta\right)=0$. By the envelope theorem,

$$
\frac{\partial G\left(\widetilde{\alpha}_{1}+\tau, \delta\right)}{\partial \tau}=\frac{\partial \pi^{*}\left(k_{1}^{*}, x_{1}^{*}, 1 ; \alpha_{1}, \delta\right)}{\partial \alpha_{1}}<0
$$

so as $\tau$ decreases, $G$ gets larger, reaching a maximum (for a given $\delta$ ) at $\tau=0$. 
Define $\tau_{m}$ by $G\left(\widetilde{\alpha}_{1}+\tau_{m}, \delta\right) \equiv F$. For $F<G\left(\widetilde{\alpha}_{1}+0, \delta\right)$, there exists $\tau_{m} \in\left(0, \alpha_{0}-\widetilde{\alpha}_{1}\right)$ such that $G\left(\delta, \widetilde{\alpha}_{1}+\tau\right)<F$ if and only if $\tau>\tau_{m}$.

Differentiating $G\left(\widetilde{\alpha}_{1}+\tau_{m}, \delta\right) \equiv F$ implicitly with respect to $\delta$ and rearranging yields

$$
\frac{d \tau_{m}}{d \delta}=-\frac{\partial G / \partial \delta}{\partial G / \partial \tau}
$$

Since the numerator is positive (see Result 2.1) and the denominator is negative, $\frac{d \tau_{m}}{d \delta}>0$.

Proof of Results 1 and 3.3. When production has moved offshore, we replace $\alpha$ with $\tilde{\alpha}_{1}+\tau$ and write the first order conditions as:

$$
\begin{aligned}
& \pi_{x}=k\left(p^{\prime}(x) x+p(x)-\left(\widetilde{\alpha}_{1}+\tau\right)-S^{\prime}(k x)\right)=0 \\
& \pi_{k}=p(x) x-\left(\widetilde{\alpha}_{1}+\tau\right) x-S^{\prime}(k x) x-\frac{c^{\prime}(k)}{\delta}=0 .
\end{aligned}
$$

Differentiating with respect to $\delta$ and $\tau$, we obtain the following system of equations:

$$
\left(\begin{array}{cc}
\pi_{x x} & \pi_{x k} \\
\pi_{k x} & \pi_{k k}
\end{array}\right)\left(\begin{array}{cc}
\frac{d x^{*}}{d \tau} & \frac{d x^{*}}{d \delta} \\
\frac{d k^{*}}{d \tau} & \frac{d k^{*}}{d \delta}
\end{array}\right)=\left(\begin{array}{cc}
-\frac{\partial \pi_{x}}{\partial \tau} & -\frac{\partial \pi_{x}}{\partial \delta} \\
-\frac{\partial \pi_{k}}{\partial \tau} & -\frac{\partial \pi_{k}}{\partial \delta}
\end{array}\right)=\left(\begin{array}{cc}
k & 0 \\
x & -\frac{c^{\prime}(k)}{\delta^{2}}
\end{array}\right)
$$

which we solve using Cramer's Rule to obtain:

$$
\left(\begin{array}{c}
\frac{d x^{*}}{d \tau} \\
\frac{d k^{*}}{d \tau} \\
\frac{d x^{*}}{d \delta} \\
\frac{d k^{*}}{d \delta}
\end{array}\right)=\frac{1}{|\mathbf{H}|}\left(\begin{array}{c}
k \pi_{k k}-x \pi_{x k} \\
x \pi_{k k}-k \pi_{x k} \\
\frac{c^{\prime}(k)}{\delta} \pi_{x k} \\
-\frac{c^{\prime}(k)}{\delta} \pi_{x x}
\end{array}\right)=\frac{1}{|\mathbf{H}|}\left(\begin{array}{c}
-k \frac{c^{\prime \prime}(k)}{\delta} \\
k x\left(p^{\prime \prime}(x) x+2 p^{\prime}(x)\right) \\
-\frac{c^{\prime}(k)}{\delta^{2}} k x S^{\prime \prime}(k x) \\
-\frac{c^{\prime}(k)}{\delta^{2}} k\left(p^{\prime \prime}(x) x+2 p^{\prime}(x)-k S^{\prime \prime}(k x)\right)
\end{array}\right),
$$


where $|\mathbf{H}|$ is the determinant of the Hessian matrix,

$$
\begin{aligned}
|\mathbf{H}| \equiv & \pi_{x x} \pi_{k k}-\pi_{x k}^{2} \\
= & -k\left(p^{\prime \prime}(x) x+2 p^{\prime}(x)-k S^{\prime \prime}(k x)\right)\left(x^{2} S^{\prime \prime}(k x)+\frac{c^{\prime \prime}(k)}{\delta}\right) \\
& -\left(p^{\prime}(x) x+p(x)-\left(\widetilde{\alpha}_{1}+\tau\right)-S^{\prime}(k x)-k x S^{\prime \prime}(k x)\right)^{2} .
\end{aligned}
$$

At the optimum, this expression simplifies since $p^{\prime}(x) x+p(x)-\left(\widetilde{\alpha}_{1}+\tau\right)-S^{\prime}(k x)=0$.

By the second-order condition, $|\mathbf{H}|>0$, so $\frac{d k^{*}}{d \tau}<0, \frac{d x^{*}}{d \tau}<0$ and $\frac{d k^{*}}{d \delta}>0, \frac{d x^{*}}{d \delta}>0$. Therefore, total import volume increases with $\delta$ and falls with $\tau: \frac{d\left(k^{*} x^{*}\right)}{d \tau}<0$ and $\frac{d\left(k^{*} x^{*}\right)}{d \delta}>0$. Import value also moves in the same direction:

$$
\begin{aligned}
& \frac{d\left(k^{*} x^{*} p\left(x^{*}\right)\right)}{d \tau}=k^{*}\left(p\left(x^{*}\right)+x^{*} p^{\prime}\left(x^{*}\right)\right) \frac{d x^{*}}{d \tau}+x^{*} p\left(x^{*}\right) \frac{d k^{*}}{d \tau} \quad<0 \\
& \frac{d\left(k^{*} x^{*} p\left(x^{*}\right)\right)}{d \delta}=k^{*}\left(p\left(x^{*}\right)+x^{*} p^{\prime}\left(x^{*}\right)\right) \frac{d x^{*}}{d \delta}+x^{*} p\left(x^{*}\right) \frac{d k^{*}}{d \delta}>0 .
\end{aligned}
$$

Proof of Result 4. Part 1 follows from applications of the envelope theorem to Equation 7, to obtain $\frac{d \pi^{*}}{d \alpha}<0$ and $\frac{d \pi^{*}}{d F}<0$.

Part 2 follows from differentiating both sides of Equation (7) with respect to $\delta$, applying the envelope theorem, and rearranging:

$$
\frac{d m}{d \delta}=\left(\frac{c\left(k^{*}\left(\alpha_{1}+m\right)\right)-c\left(k^{*}\left(\alpha_{1}\right)\right)}{\delta^{2} \cdot k^{*}\left(\alpha_{1}+m\right) \cdot x^{*}\left(\alpha_{1}+m\right)}\right)<0
$$

The numerator is positive because $m>0$ and (from Lemma 1) $k^{*}$ is decreasing in $\alpha$.

Finally, differentiating both sides of Equation (7) with respect to $\alpha_{1}$, applying the envelope theorem, and rearranging:

$$
\frac{d m}{d \alpha_{1}}=\frac{k^{*}\left(\alpha_{1}\right) \cdot x^{*}\left(\alpha_{1}\right)-k^{*}\left(\alpha_{1}+m\right) \cdot x^{*}\left(\alpha_{1}+m\right)}{k^{*}\left(\alpha_{1}+m\right) \cdot x^{*}\left(\alpha_{1}+m\right)}>0
$$


since $m>0$ and (again from Lemma 1 ) both $k^{*}$ and $x^{*}$ are decreasing in $\alpha$.

\section{B Data Appendix}

We use BLS price indices for the years 1984-2003 to compute apparel CPI inflation in 23 geographic markets (MSAs) (denoted $\Delta p_{i t}$ ) as the year-to-year log change in each MSA's apparel CPI. The BLS price indices can be obtained from the BLS web site, http://www.bls.gov/cpi/. The MSAs used in the analysis are: Anchorage; Atlanta; Boston-Brockton-Nashua; ChicagoGary-Kenosha; Cincinnati-Hamilton; Cleveland-Akron; Dallas-Fort Worth; Denver-BoulderGreeley; Detroit-Ann Arbor-Flint; Honolulu; Houston-Galveston-Brazoria; Kansas City; Los Angeles-Riverside-Orange County; Miami-Fort Lauderdale; Milwaukee-Racine; MinneapolisSt. Paul; Philadelphia-Wilmington-Atlantic City; Pittsburgh; Portland-Salem; St. Louis; San Diego; San Francisco-Oakland-San Jose; Seattle-Tacoma-Bremerton. ${ }^{34}$

We also compute Wal-Mart's market share in each MSA each year, denoted WMshare ${ }_{i t}$, as the ratio of the number of existing Wal-Mart stores in the MSA to the number of all retail establishments specializing in apparel or "general merchandise" sales. The relevant number of retail establishments is computed by adding up the number of establishments across all counties within each MSA for SIC codes 5300 (general merchandise) and 5600 (apparel) for 1985-1997, and for NAICS codes 452 and 448 thereafter, from County Business Patterns. ${ }^{35}$

The number of existing Wal-Mart stores in each MSA each year come from available historical lists of Wal-Mart store locations. For 1985-1993 we use the annual publication Directory of Discount Stores published by Chain Store Guides; for 1994-2003 we use the

\footnotetext{
${ }^{34}$ The results are not sensitive to the inclusion or exclusion of the New York-Northern New Jersey-Long Island MSA, which had no Wal-Mart stores throughout the period.

${ }^{35}$ Despite the shift from SIC to NAICS after 1997, we find no break in the numbers of establishments before and after this shift, suggesting that the mapping from SIC to NAICS is fairly straightforward for these two classifications. County Business Patterns data can be obtained from http://www.census.gov/epcd/cbp/view/cbpview.html.
} 
Wal-Mart editions of the road atlas published by Rand McNally, which contain complete store lists (see Basker (2005a,b) for details on the data set construction). We supplement these lists with data from press releases, available on Wal-Mart's web site, about more recent store openings. $36 \quad 37$

Finally, we obtain the apparel import price index from the BLS web site, http://www . bls .gov/mxp/. We use the import price index for Standard International Trade Classification (SITC) code 84 and for end-use classification code 400. We compute the import inflation rate (denoted $\Delta p_{t}^{m}$ ) for both indices using December-to-December log changes in the value of the index.

\footnotetext{
${ }^{36}$ The press releases are available from http://www . walmartstores . com/wmstore/wmstores/HomePage. jsp. Special care needs to be taken using them, however, since new openings, store renovations, and conversions of "discount stores" to "supercenters" are often not distinguished in the releases. To circumvent this problem we match all press release data against the list of existing stores to ensure that we do not double count stores.

${ }^{37}$ Results are virtually identical if error-free administrative data from Basker (2006) are used instead.
} 


\section{References}

Abernathy, F. H., J. T. Dunlop, J. H. Hammond, and D. Weil (1999) A Stitch in Time: Lean Retailing and the Transformation of Manufacturing - Lessons from the Apparel and Textile Industries. Oxford University Press, New York and Oxford.

Acemoglu, D. (2002) "Directed Technical Change," Review of Economic Studies, 69(4), 781809.

Alessandria, G., and H. Choi (2007) "Do Sunk Costs of Exporting Matter for Net Export Dynamics?," Quarterly Journal of Economics, 122(1), 289-336.

Antràs, P. (2003) "Firms, Contracts, and Trade Structure," Quarterly Journal of Economics, 118(4), 1374-1418.

Antràs, P., and E. Helpman (2004) "Global Sourcing," Journal of Political Economy, 112(3), $552-580$.

Antweiler, W., and D. Trefler (2002) "Increasing Returns and All That: A View from Trade," American Economic Review, 2(1), 93-119.

Bagwell, K., G. Ramey, and D. F. Spulber (1997) "Dynamic Retail Price and Investment Competition," RAND Journal of Economics, 28(2), 207-227.

Basker, E. (2005a) "Job Creation or Destruction? Labor-Market Effects of Wal-Mart Expansion," Review of Economics and Statistics, 87(1), 174-183.

_ (2005b) "Selling a Cheaper Mousetrap: Wal-Mart's Effect on Retail Prices," Journal of Urban Economics, 58(2), 203-229.

— (2006) "When Good Instruments Go Bad," unpublished paper, University of Missouri.

(2007) "The Causes and Consequences of Wal-Mart's Growth," Journal of Economic Perspectives, 21(3), 177-198.

Basker, E., S. D. Klimek, and P. H. Van (2008) "Supersize It: The Growth of Chains and the Rise of the Big Box Retail Format," unpublished paper, University of Missouri.

Basker, E., and P. H. Van (2006) "Putting a Smiley Face on the Dragon: Wal-Mart as Catalyst to U.S.-China Trade," unpublished paper, University of Missouri.

— (2008) "Imports "Я" Us," unpublished paper, University of Missouri.

Belassa, B. (1967) Trade Liberalization Among Industrial Countries: Objectives and Alternatives. McGraw-Hill, New York.

Bernard, A., J. B. Jensen, and P. Schott (forthcoming) "Importers, Exporters and Multinationals: A Portrait of Firms in the U.S. that Trade Goods," in Producer Dynamics: New Evidence from Micro Data, ed. by T. Dunne, J. B. Jensen, and M. J. Roberts. University of Chicago Press. 
Bernard, A., S. J. Redding, and P. K. Schott (2006) "Multi-Product Firms and Trade Liberalization," National Bureau of Economic Research Working Paper 12782.

Campbell, J. R., and B. Lapham (2004) "Real Exchange Rate Fluctuations and the Dynamics of Retail Trade Industries on the U.S.-Canada Border," American Economic Review, 94(4).

Chevalier, J. A., A. K. Kashyap, and P. E. Rossi (2003) "Why Don't Prices Rise During Periods of Peak Demand? Evidence from Scanner Data," American Economic Review, 93(1), 15-37.

Chiou, L. (2005) "Empirical Analysis of Retail Competition: Spatial Differentiation at WalMart, Amazon.com, and Their Competitors," unpublished paper, Occidental College.

Doms, M. E., R. S. Jarmin, and S. D. Klimek (2004) "Information Technology Investment and Firm Performance in U.S. Retail Trade," Economics of Innovation and New Technology, 13(7), 595-613.

The Economist (2004) "How Big Can It Grow? — Wal-Mart," The Economist, April 17, 2004.

Ethier, W. (1979) "Internationally Decreasing Costs and World Trade," Journal of International Economics, 9(1), 1-24.

Evans, C., and J. Harrigan (2005) "Distance, Time, and Specialization: Lean Retailing in General Equilibrium," American Economic Review, 95(1), 292-313.

Feenstra, R., and G. Hanson (2005) "Ownership and Control in Outsourcing to China: Estimating the Property-Rights Theory of the Firm," Quarterly Journal of Economics, 120(2), 729-761.

Feenstra, R. C., and G. G. Hamilton (2006) Emergent Economies, Divergent Paths: Economic Organization and International Trade in South Korea and Taiwan. Cambridge University Press, New York.

Feiner, J. M., A. H. O'Andraia, J. Black, C. E. Jones, and R. J. Konik (2002) Wal-Mart Encyclopedia XI. Lehman Brothers, New York.

Fishman, C. (2006) The Wal-Mart Effect. Penguin Books, New York.

Foster, L., J. Haltiwanger, and C. J. Krizan (2002) "The Link between Aggregate and Micro Productivity Growth: Evidence from Retail Trade," National Bureau of Economic Research Working Paper 9120.

Gereffi, G. (1994) "Buyer-Driven Global Commodity Chains," in Commodity Chains and Global Capitalism, ed. by G. Gereffi, and M. Korzeniewicz, pp. 95-122. Westport, CT and London: Praeger.

(1999) "International Trade and Industrial Upgrading in the Apparel Commodity Chain," Journal of International Economics, 48(1), 37-70. 
- (2006) "The New Offshoring of Jobs and Global Development," unpublished manuscript, Duke University.

Gereffi, G., and M.-L. Pan (1994) "The Globalization of Taiwan's Garment Industry," in Global Production: The Apparel Industry in the Pacific Rim, ed. by E. Bonacich, L. Cheng, N. Chinchilla, N. Hamilton, and P. Ong, pp. 126-146. Philadelphia: Temple University Press.

Gladstone, R. (1992) "No. 1 Retailer Slammed in 'Dateline NBC' Show, Stock Falls," Associated Press, December 21, 1992.

Goldman, A., and N. Cleeland (2003) "An Empire Built on Bargains Remakes the Working World," Los Angeles Times, November 23, 2003.

Goodman, P. S., and P. P. Pan (2004) "Chinese Workers Pay for Wal-Mart's Low Prices; Retailer Squeezes Its Asian Suppliers to Cut Costs," The Washington Post, February 8, 2004.

Grossman, G., and E. Helpman (2002a) "Integration versus Outsourcing in Industry Equilibrium," Quarterly Journal of Economics, 117(2), 85120.

— (2002b) "Outsourcing in a Global Economy," National Bureau of Economic Research Working Paper 8728.

Hausman, J., and E. Leibtag (2004) "CPI Bias from Supercenters: Does the BLS Know that Wal-Mart Exists?," National Bureau of Economic Research Working Paper 10712.

Helpman, E., and P. Krugman (1985) Market Structure and Foreign Trade. MIT Press, Cambridge, MA.

Holmes, T. (2001) "Bar Codes Lead to Frequent Deliveries and Superstores," RAND Journal of Economics, 32(4), 708-725.

- (2008) "The Diffusion of Wal-Mart and Economies of Density," National Bureau of Economic Research Working Paper 13783.

Hummels, D. (1999) "Have International Transportation Costs Declined?," unpublished paper, University of Chicago.

Jarmin, R. S., S. D. Klimek, and J. Miranda (2005) "The Evolution of Retail Markets in Metropolitan, Micropolitan and Rural Regions," unpublished paper, U.S. Census Bureau.

Javorcik, B. S., W. Keller, and J. Tybout (2006) "Openness and Industrial Responses in a Wal-Mart World: A Case Study of Mexican Soaps, Detergents and Surfactant Producers," National Bureau of Economic Research Working Paper 12457.

Jiang, J. (2004) "Wal-Mart's China Inventory to Hit U.S.\$18 Billion," China Business Weekly, November 30, 2004. 
Jones, R. W., and H. Kierzkowski (1990) "The Role of Services in Production and International Trade: A Theoretical Framework," in The Political Economy of International Trade: Essays in Honor of Robert E. Baldwin, ed. by R. W. Jones, and A. O. Krueger, pp. 31-48. Basil Blackwell, Cambridge, MA.

Koeva, P. (2000) "The Facts about Time-to-Build," IMF Working Paper WP/00/138.

Long, N. V., R. Riezman, and A. Souberyan (2005) "Fragmentation and Services," North American Journal of Economics and Finance, 16(1), 137-152.

McKinsey Global Institute (2001) "U.S. Productivity Growth 1995-2000: Understanding the Contribution of Information Technology Relative to Other Factors," McKinsey Global Institute.

Melitz, M. J. (2003) "The Impact of Trade on Intra-Industry Reallocations and Aggregate Industry Productivity," Econometrica, 71(6), 1695-1725.

Moreira, M. M. (2007) "Fear of China: Is There a Future for Manufacturing in Latin America?," World Development, 35(3), 355-376.

Petrovic, M., and G. G. Hamilton (2005) "Making Global Markets: Wal-Mart and Its Suppliers," unpublished paper, University of Washington.

Riper, T. V. (2007) “The Wal-Mart Squeeze," Forbes, April 24, 2007.

Romalis, J. (2005) "Market Access, Openness and Growth," unpublished paper, University of Chicago.

Ruhl, K. J. (2008) "The International Elasticity Puzzle," unpublished paper, University of Texas.

Smith, A. (1776) An Inquiry into the Nature and Causes of the Wealth of Nations. Strahan and Cadell, London.

Swenson, D. L. (2005) "Overseas Assembly and Country Sourcing Choices," Journal of International Economics, 66(1), 107-230.

Wal-Mart Stores, Inc. (2005) "Wal-Mart Announces Plans to Add Over 60 Million Square Feet of Gross Retail Space," October 24, 2005.

- (various years) Wal-Mart Annual Report.

Wan, H. Y. (2005) "Fragmented Trade and Manufacturing Services-Examples for a NonConvex General Equilibrium," International Review of Economics and Finance, 14(3), 273-295.

Westerman, P. (2001) Data Warehousing: Using the Wal-Mart Model. Morgan Kaufmann Publishers, San Francisco. 
Yi, K.-M. (2003) "Can Vertical Specialization Explain the Growth of World Trade?," Journal of Political Economy, 111(1), 52-102.

Zellner, W. (1992) "How True-Blue is Wal-Mart's 'Buy American' Pledge?," Business Week, March 16, 1992. 
Table 1. Growth of Retail Chains, 1948-1997 ${ }^{\mathrm{a}}$

\begin{tabular}{|c|c|c|c|c|c|c|}
\hline & \multicolumn{3}{|c|}{ Chains' Share of All } & \multicolumn{3}{|c|}{$\begin{array}{l}\text { Large Chains' Share } \\
\text { of All Chains' }\end{array}$} \\
\hline & Firms & Stores & Sales & Firms & Stores & Sales \\
\hline 1948 & & $9.2 \%$ & $29.6 \%$ & & $27.2 \%$ & $41.6 \%$ \\
\hline 19 & & $\%$ & & & $\%$ & $41.8 \%$ \\
\hline 19 & & $\%_{0}$ & & & $27.5 \%$ & $42.4 \%$ \\
\hline 19 & 2.85 & 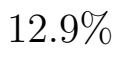 & & $44 \%$ & $31.8 \%$ & $43.2 \%$ \\
\hline 19 & 2. & 1 & 39 & 8 & $37.6 \%$ & $46.7 \%$ \\
\hline 19 & 2. & 15. & 45 & .6 & $40.2 \%$ & $55.8 \%$ \\
\hline 198 & $3.24 \%$ & $20.9 \%$ & 52. & $0.74 \%$ & $45.5 \%$ & $56.5 \%$ \\
\hline 1992 & $4.95 \%$ & $33.6 \%$ & $58.2 \%$ & $1.02 \%$ & $51.5 \%$ & $58.8 \%$ \\
\hline $1997^{\mathrm{b}}$ & $5.12 \%$ & $37.5 \%$ & $61.2 \%$ & $1.32 \%$ & $56.6 \%$ & $61.0 \%$ \\
\hline $2002^{b}$ & $4.33 \%$ & $37.6 \%$ & $62.8 \%$ & $1.45 \%$ & $61.8 \%$ & $68.4 \%$ \\
\hline
\end{tabular}

Source: authors' calculations from Census of Business (various years) and Census of Retail Trade (various years)

${ }^{\text {a }}$ Chains include multi-unit retailers with more than one unit; large chains include chains with 101+ stores for 1948-1972, 100+ stores in 1982-1997

b Classification by SIC 1948-1992, NAICS thereafter.

Table 2. Regression Results for Consumer Price Inflation

\begin{tabular}{|c|c|c|c|c|}
\hline & \multicolumn{2}{|c|}{ SITC Import Inflation } & \multicolumn{2}{|c|}{ End-Use Import Inflation } \\
\hline & (1) & $(2)$ & (3) & (4) \\
\hline \multirow{4}{*}{$\Delta P_{t}^{m}$} & 0.4331 & 0.3036 & 0.5123 & 0.3657 \\
\hline & $(0.0722)^{* * *}$ & $(0.0848) * * *$ & $(0.0687)^{* * *}$ & $(0.0835)^{* * *}$ \\
\hline & $(0.0439)^{* * *}$ & $(0.0505) * * *$ & $(0.0423)^{* * *}$ & $(0.0502)^{* * *}$ \\
\hline & $(0.1820)^{* *}$ & $(0.1769)$ & $(0.1376)^{* * *}$ & $(0.1326)^{* *}$ \\
\hline \multirow{4}{*}{ WMshare $_{i t}$} & & -1.2754 & & -1.1159 \\
\hline & & $(0.3010)^{* * *}$ & & $(0.3482)^{* * *}$ \\
\hline & & $(0.3739)^{* * *}$ & & $(0.3574)^{* * *}$ \\
\hline & & $(0.4254)^{* * *}$ & & $(0.3961)^{* *}$ \\
\hline \multirow{4}{*}{$\Delta P_{t}^{m} \cdot$ WMshare $_{i t}$} & & 24.3187 & & 25.9046 \\
\hline & & $(14.0860)^{*}$ & & $(13.2896)^{*}$ \\
\hline & & $(6.8626)^{* * *}$ & & $(9.8475)^{* *}$ \\
\hline & & $(9.5233)^{* *}$ & & $(11.9003)^{* *}$ \\
\hline Observations & 437 & 437 & 437 & 437 \\
\hline
\end{tabular}

Note: Standard errors in parentheses, respectively: unclustered, clustered by MSA, clustered by year. ${ }^{*}$ significant at $10 \%$; ${ }^{*}$ significant at $5 \%$; ${ }^{* *}$ significant at $1 \%$ 
Table 3. Parameter and Variable Estimates

\begin{tabular}{ccll}
\hline \multicolumn{2}{c}{ Time Invariant } & \multicolumn{2}{c}{ Time Varying (1994) } \\
\hline \hline$A$ & 535.82 & $\alpha$ & 1 \\
$\varepsilon$ & 3.2075 & $p$ & 3.837 \\
$\sigma$ & 0.8 & $x$ & $7,588 \cdot 10^{3}$ \\
$s$ & 239.03 & $\delta$ & 0.000312 \\
\hline
\end{tabular}

Table 4. Tariff Elasticity of Sales, 1994

\begin{tabular}{lccccc}
\hline \multicolumn{1}{c}{$\sigma$} & $\begin{array}{c}\text { Demand } \\
\text { Effect }\end{array}$ & $\begin{array}{c}\text { Expansion } \\
\text { Effect }\end{array}$ & $\begin{array}{c}\text { Scale } \\
\text { Effect }\end{array}$ & $\begin{array}{c}\text { Total } \\
\text { Elasticity }\end{array}$ & $\begin{array}{c}\text { Demand Share } \\
\text { of Total }\end{array}$ \\
\hline \hline 0.7 & -3.478 & -2.051 & -2.197 & -7.727 & $45 \%$ \\
0.75 & -3.030 & -1.758 & -2.097 & -6.885 & $44 \%$ \\
0.8 & -2.237 & -1.276 & -1.691 & -5.204 & $43 \%$ \\
0.85 & -0.738 & -0.413 & -0.607 & -1.759 & $42 \%$ \\
\hline
\end{tabular}

Table 5. Time-Varying Parameters and Variables, 1984-2004

\begin{tabular}{clcl}
\hline Variable & \multicolumn{1}{c}{1984} & \multicolumn{1}{c}{2004} & Log Change \\
\hline \hline$x$ & $2,113 \cdot 10^{3}$ & $13,060 \cdot 10^{3}$ & +1.82 \\
$k$ & 756 & 5289 & +1.95 \\
$p$ & 5.717 & 3.240 & -0.57 \\
$\alpha$ & 1.176 & 0.930 & -0.23 \\
$\delta$ & 0.000201 & 0.000401 & +0.69 \\
\hline
\end{tabular}

Table 6. Relative Contributions, by Variable and Channel, to Wal-Mart's Expansion, 1984-2004

\begin{tabular}{llll}
\hline & $\alpha$ & \multicolumn{1}{c}{$\delta$} & Row Sum \\
\hline \hline Demand Channel & 0.1764 & 0 & 0.1764 \\
Expansion Channel & 0.1005 & 0.3547 & 0.4553 \\
Scale Channel & 0.1333 & 0.2351 & 0.3684 \\
\hline Column Sum & 0.4102 & 0.5898 & 1
\end{tabular}




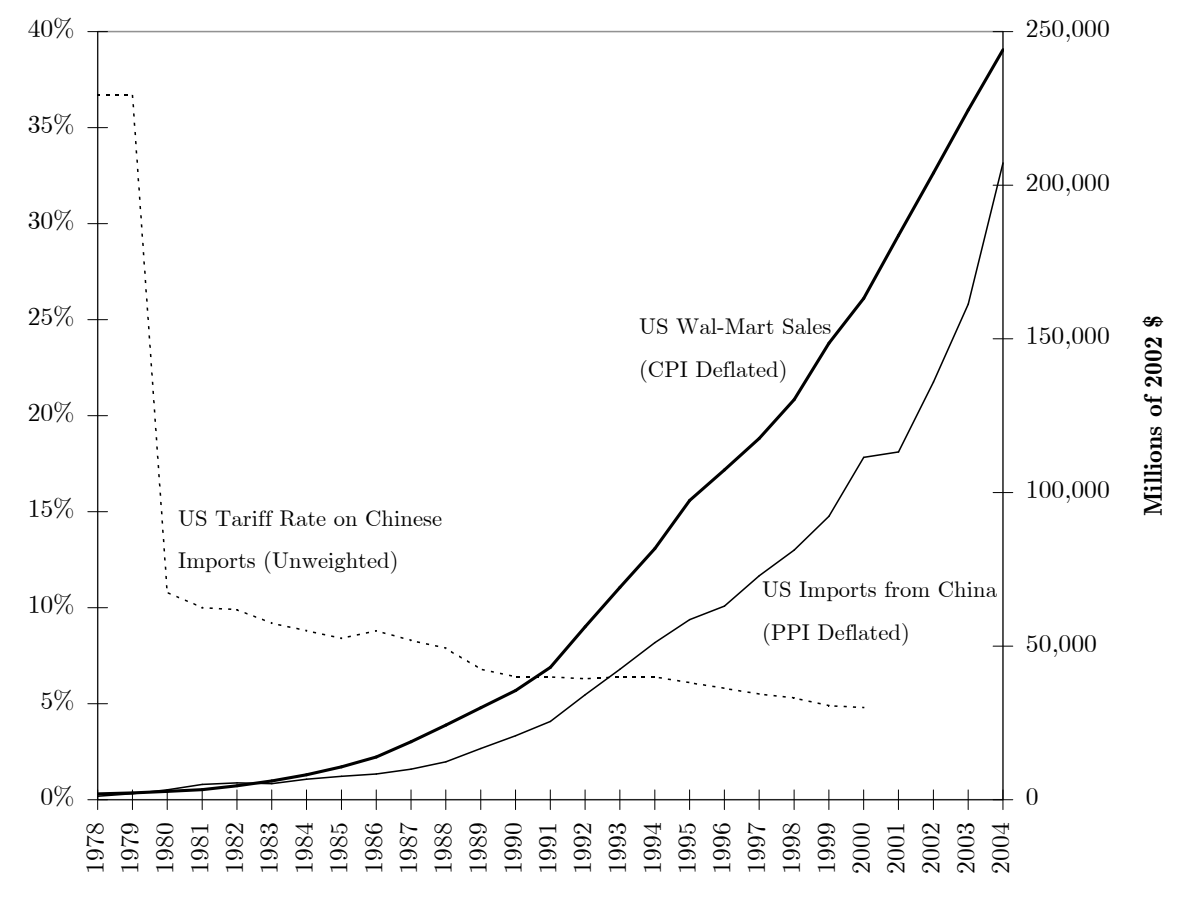

Figure 1. U.S. Tariff on Chinese Imports, U.S. Imports from China and U.S. Wal-Mart Sales

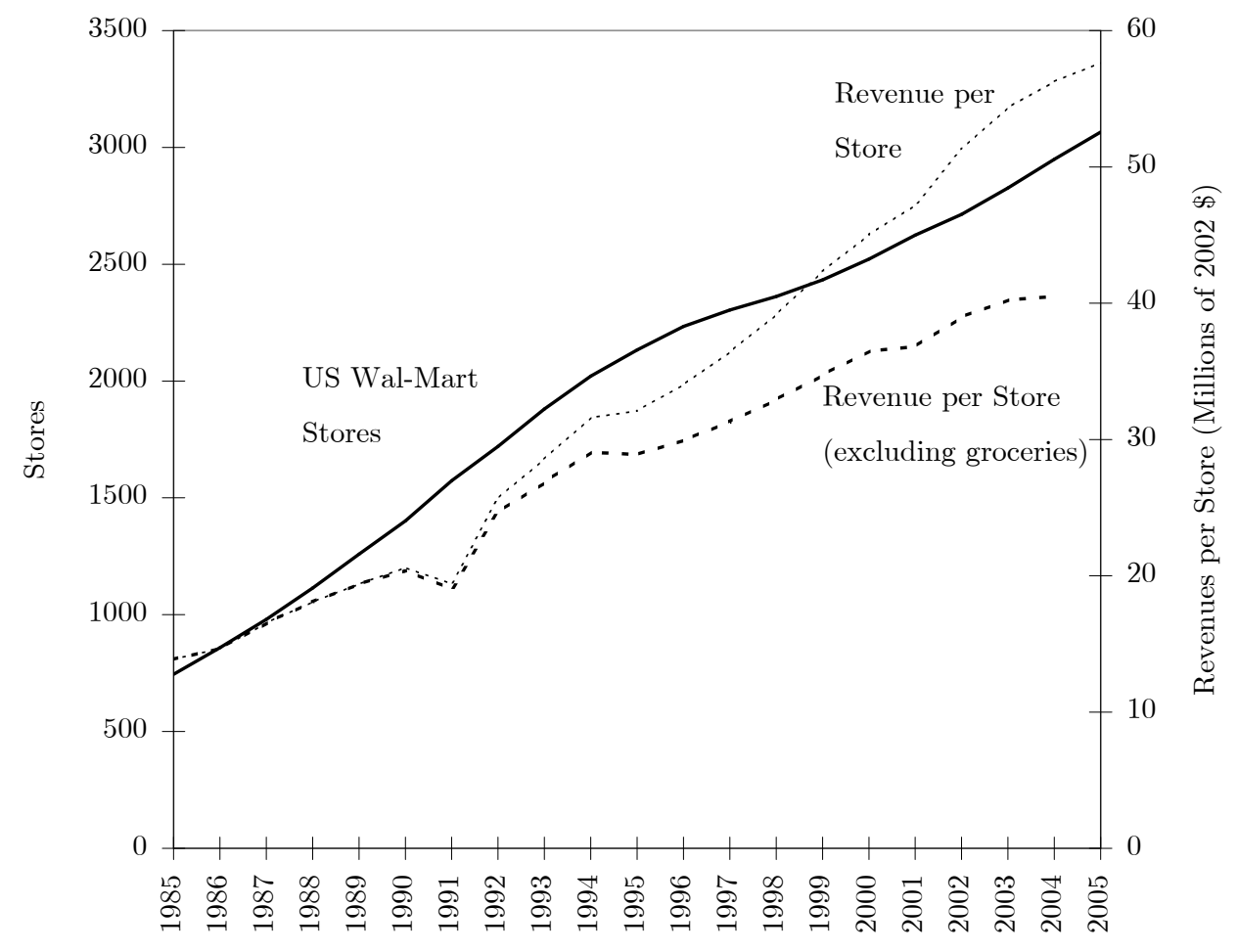

Figure 2. Wal-Mart's Growth: Stores and Average Sales per Store, 1985-2005 


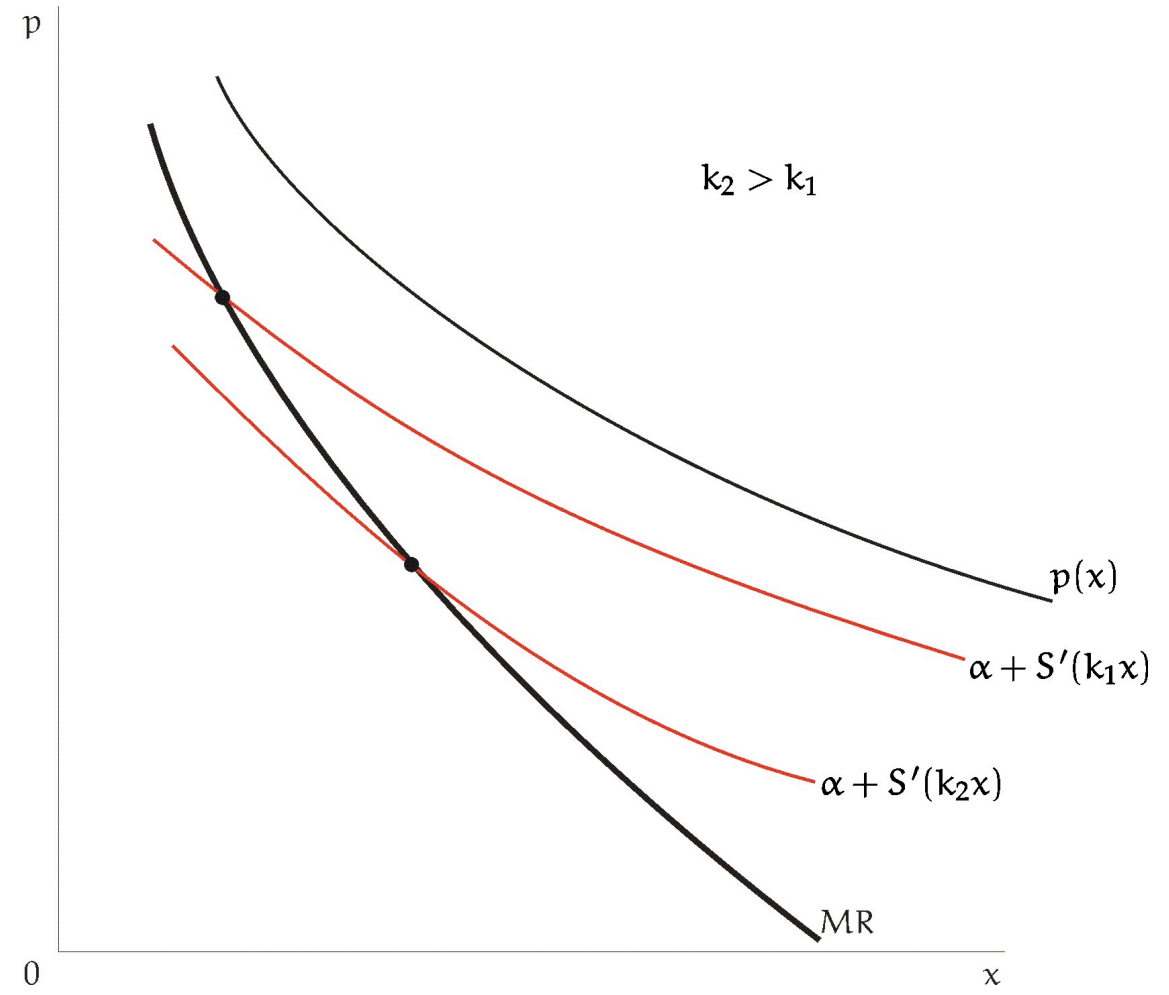

Figure 3. Determination of $x^{*}(k)$

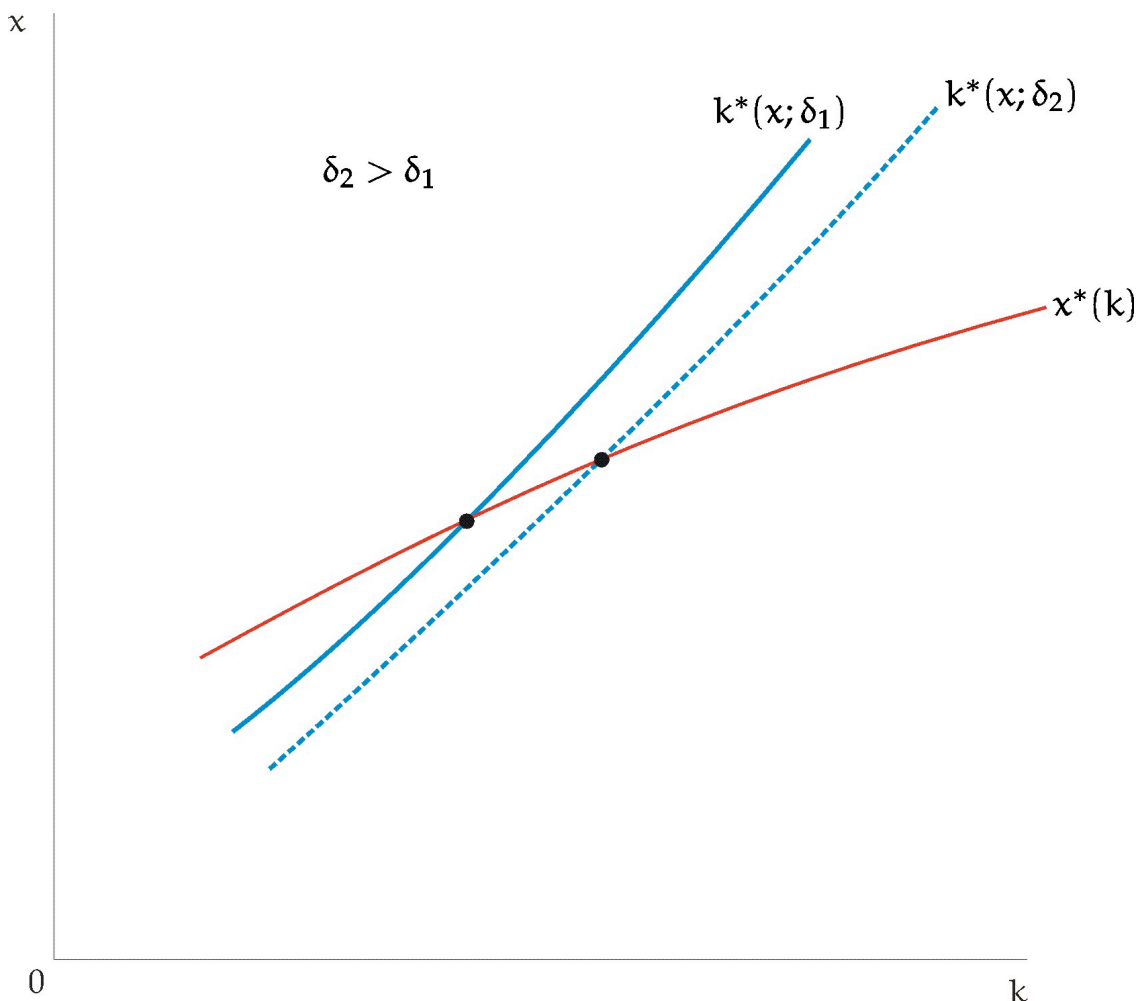

Figure 4. Equilibrium Chain Size and Quantity as Functions of $\delta$ 


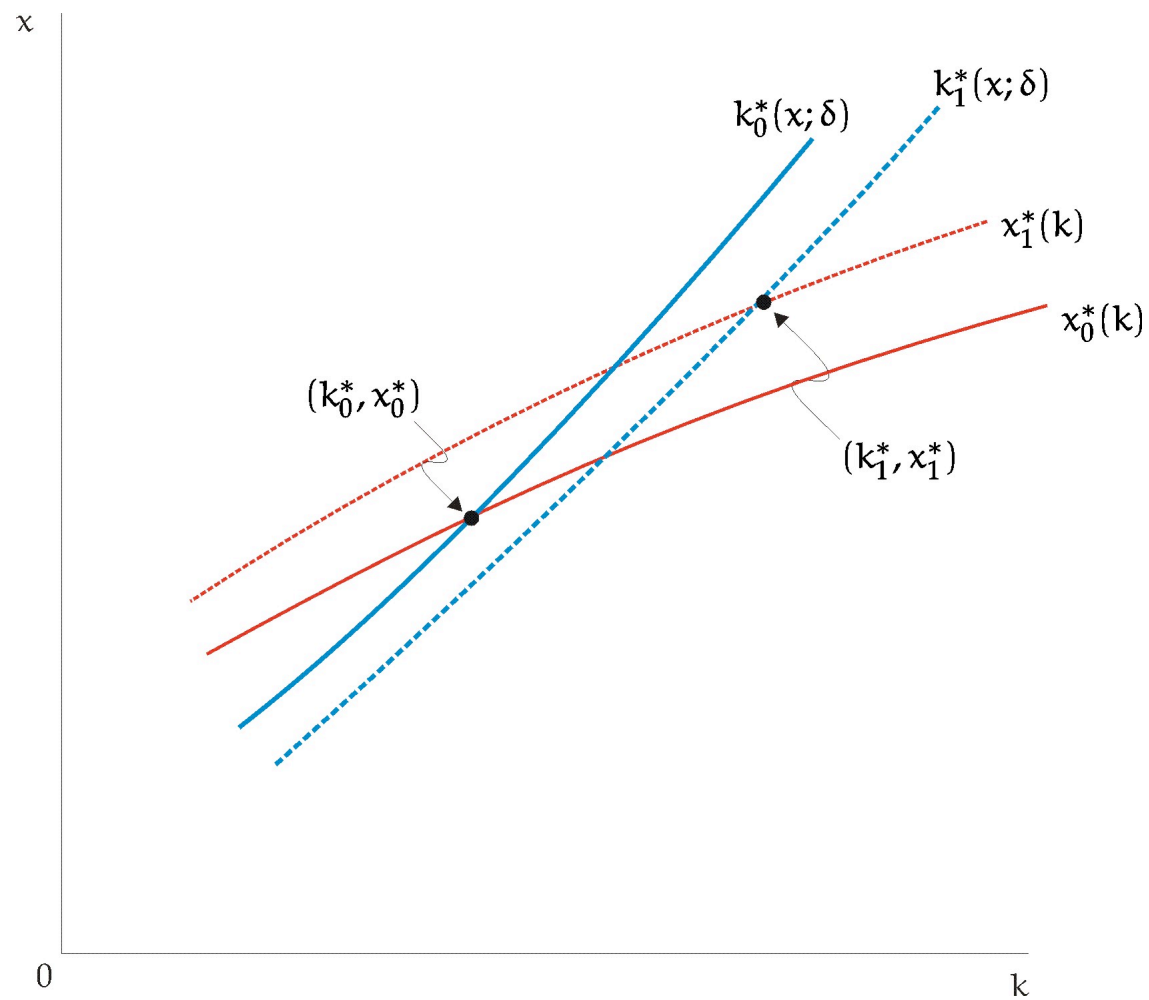

Figure 5. Equilibrium Chain Size and Quantity: Domestic vs. Foreign Production

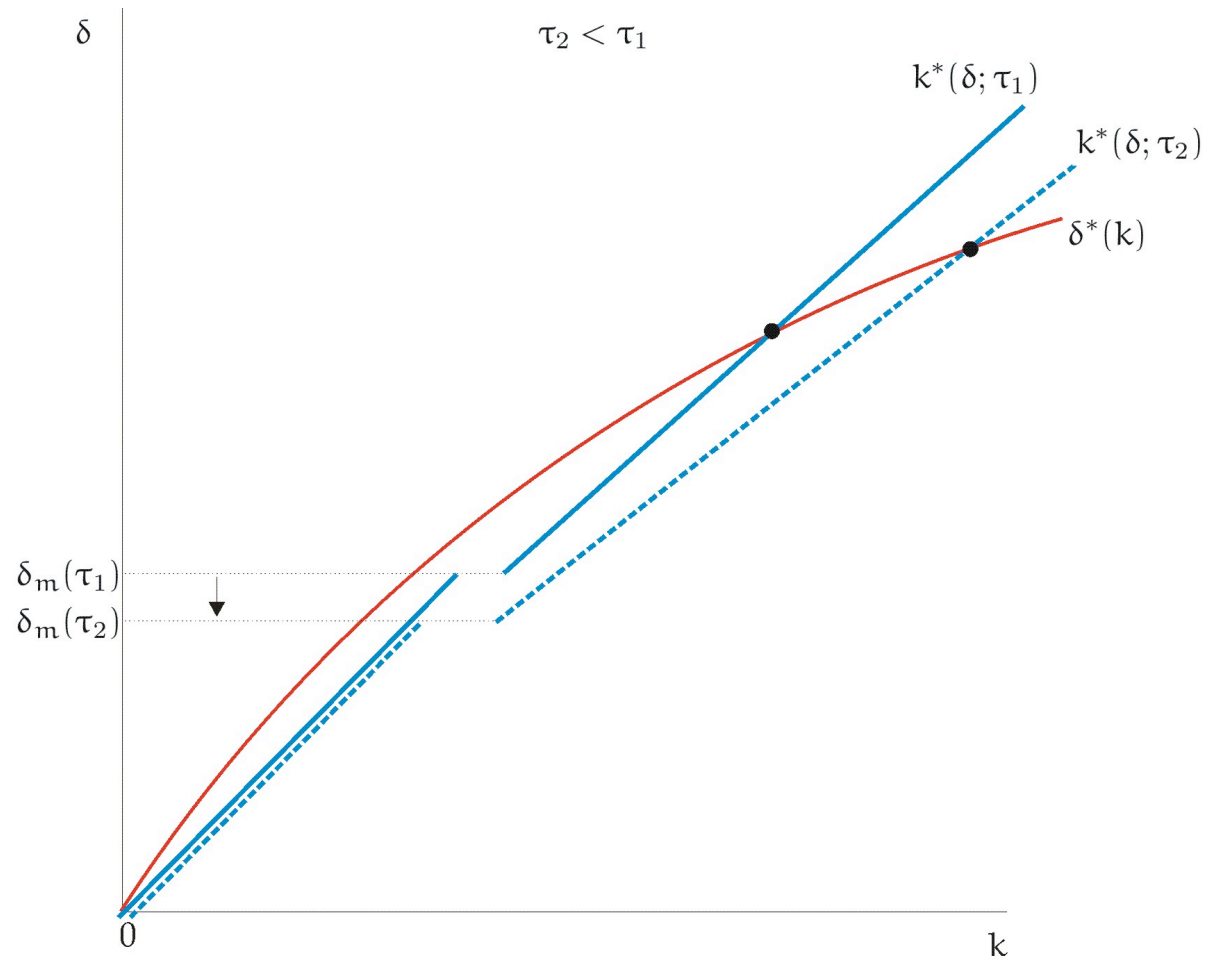

Figure 6. Endogenous Chaining Technology 


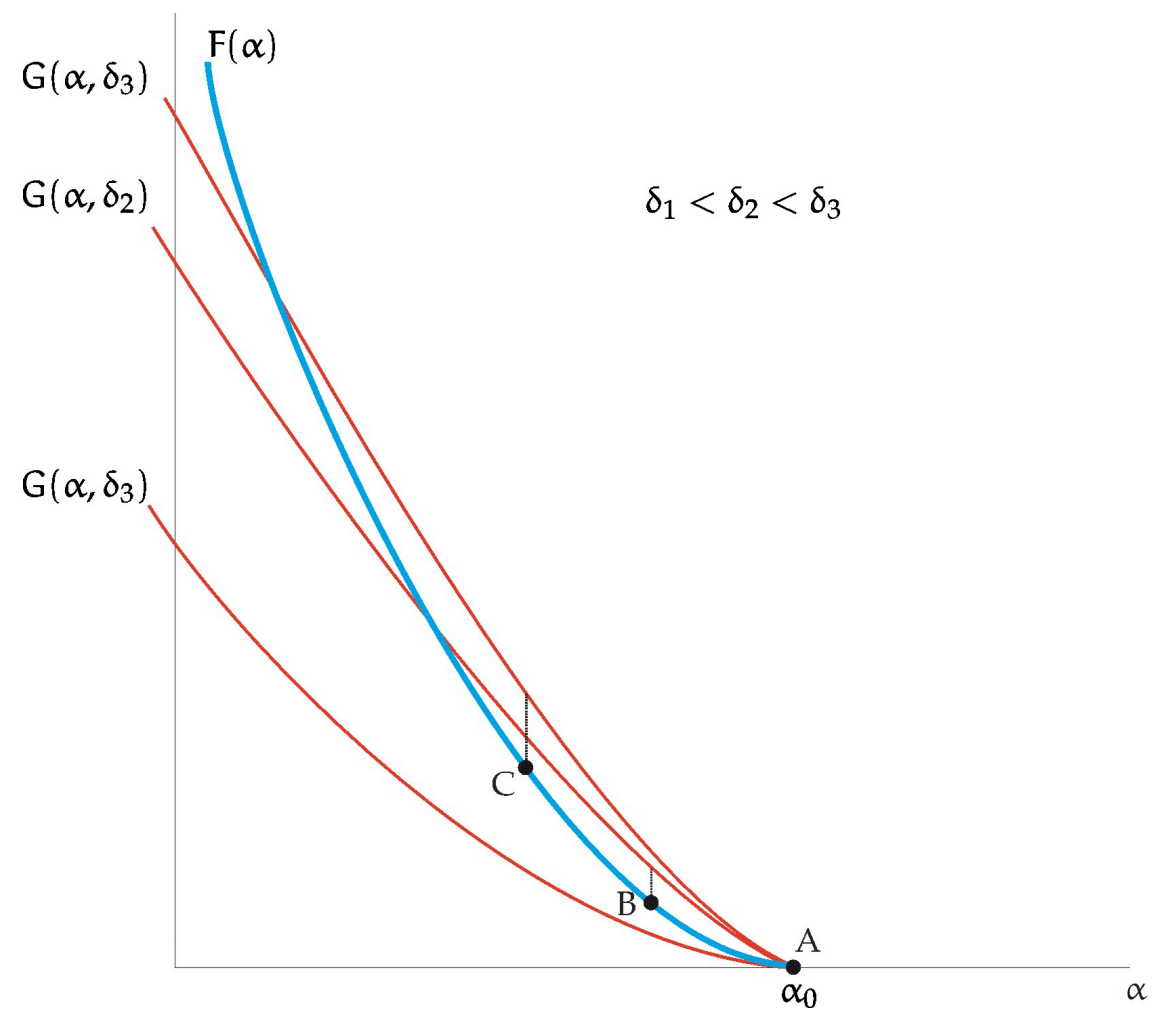

Figure 7. Location of Production and Chaining Technology

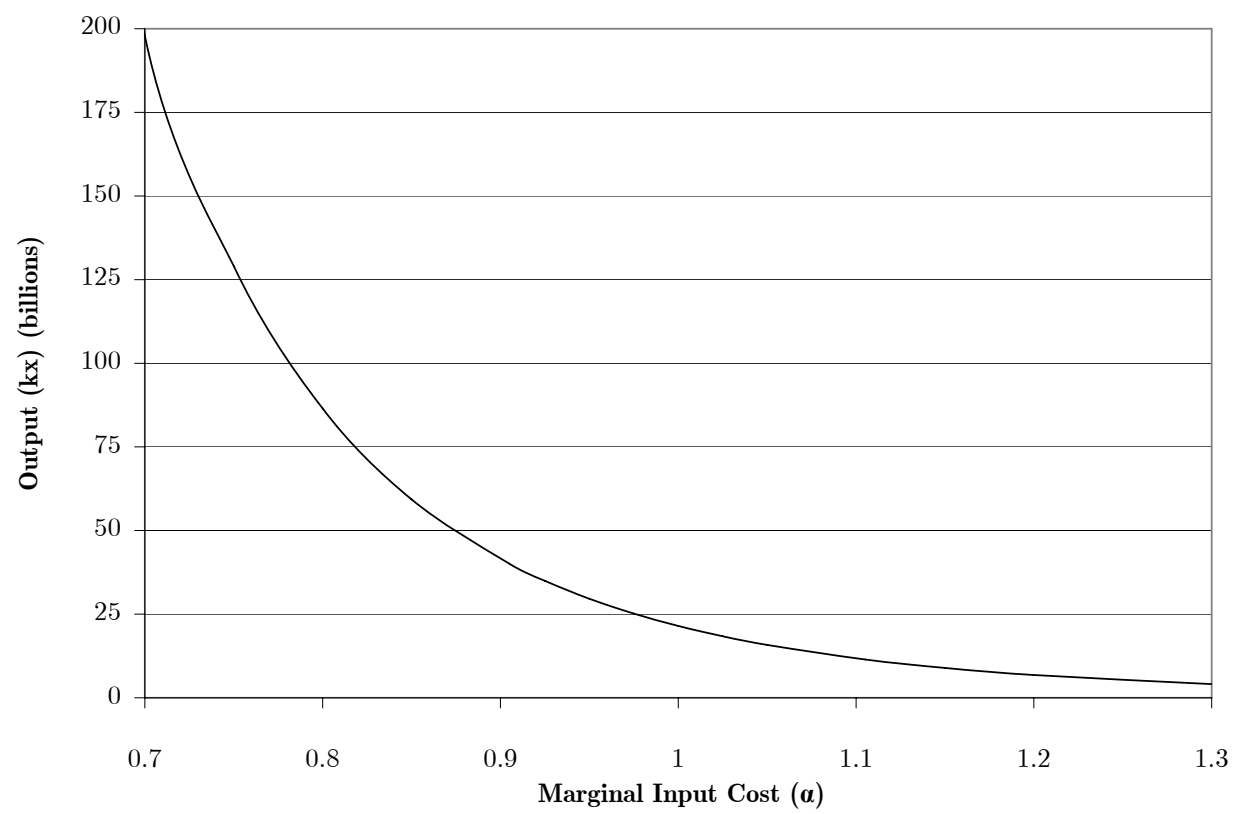

Figure 8. Simulated Sales Volume as a Function of Input Cost, 1994 